\title{
Effects of intolerance of uncertainty on subjective and psychophysiological measures during fear acquisition and delayed extinction
}

\author{
Maren Klingelhöfer-Jens ${ }^{a^{*}}$, Jayne Morriss ${ }^{b *}$, \& Tina B. Lonsdorf $f^{a}$
}

${ }^{a}$ Department of Systems Neuroscience, University Medical Center Hamburg-Eppendorf, Martinistraße 52, Bldg. W34, 20246 Hamburg, Germany.

${ }^{b}$ Centre for Integrative Neuroscience and Neurodynamics, School of Psychology and Clinical Language Sciences, University of Reading, Berkshire RG6 6AL, Reading, UK.

*These authors contributed equally.

Correspondence:

Maren Klingelhöfer-Jens

Department of Systems Neuroscience

University Medical Center Hamburg-Eppendorf

Martinistrasse 52, Bldg. 34

20251 Hamburg

Germany

m.klingelhoefer-jens@uke.de 


\begin{abstract}
Individuals who score high in self-reported Intolerance of Uncertainty (IU) tend to find uncertainty unacceptable and aversive. In recent years, research has shed light on the role of IU in modulating subjective (i.e. expectancy ratings) and psychophysiological responses (i.e. skin conductance) across different classical fear conditioning procedures. In particular, during immediate extinction higher $\mathrm{IU}$ is associated with disrupted safety learning. However, there remain gaps in understanding how IU, in comparison to other negative emotionality traits (STAIT), impact different types of subjective and psychophysiological measures during different classical fear conditioning procedures. In our exploratory study, we analyzed IU, STAI-T, subjective (i.e. fear ratings) and psychophysiological (i.e. skin conductance, auditory startle blink) data recorded during fear acquisition training and 24h-delayed extinction training $(n=66)$. Higher IU, over STAI-T, was: (1) significantly associated with greater fear ratings to the learned fear cue during fear acquisition training, and (2) at trend associated with greater fear ratings to the learned fear versus safe cue during delayed extinction training. Null results were observed for both IU and STAI-T in relation to skin conductance and auditory startle blink during fear acquisition training and delayed extinction training. These results add to and extend our current understanding of the role of IU on subjective and physiological measures during different fear conditioning procedures particularly that of subjective fear ratings during acquisition and delayed extinction training. Implications of these findings and future directions are discussed.
\end{abstract}

Keywords: Extinction, Fear, Intolerance of Uncertainty, Skin Conductance, Auditory Startle Blink, Ratings 


\section{Introduction}

The fear of the unknown is thought to play a central role in pathological fear and anxiety (Carleton, 2016a) and is considered a sub facet of the higher order construct of neuroticism, which relates to broader negative affect (Barlow et al., 2014; Carleton, 2016a; Clark \& Beck, 2011). A proxy measure of the fear of the unknown is self-reported Intolerance of Uncertainty (IU) which can be measured through standardized questionnaires (Carleton, 2016b). Individuals who score high in self-reported IU tend to find uncertainty unacceptable and aversive (Carleton et al., 2007; Freeston et al., 1994). Notably, IU is considered a transdiagnostic dimension, as high levels of self-reported IU are observed across a wide range of mental health disorders such as anxiety, trauma, and obsessive compulsive disorders (Carleton et al., 2012; McEvoy et al., 2019). Crucially, several novel intervention and clinical studies have highlighted the potential of IU as a transdiagnostic treatment target (Oglesby et al., 2017; van der Heiden et al., 2012) and trans-therapy change process (McEvoy \& Erceg-Hurn, 2016). Because of these recent advances, the spotlight has shifted to examining the neural and psychophysiological basis of IU (Tanovic et al., 2018), in order to identify IU-related mechanisms that can be targeted in therapeutic treatments (Shihata et al., 2016).

Classical fear conditioning mechanisms are commonly examined to model the development, treatment and relapse of anxiety, trauma, and obsessive compulsive disorders (Craske et al., 2014; Jacoby \& Abramowitz, 2016; McNally, 2007; Pittig et al., 2018). Classical fear conditioning procedures can be used to capture different aspects of fear and safety learning (for review see Lonsdorf et al., 2017). During fear acquisition training, a neutral stimulus (CS+: e.g. visual cue) is repeatedly paired with an aversive outcome (US: e.g. electric shock). Another stimulus (CS-) with no outcome is also typically presented (i.e. differential conditioning) and signals safety. Over the course of fear acquisition training, the CS+, relative to the CS-, elicits a conditioned response (e.g. subjective fear and/or larger physiological response). During extinction training, the CS+ is presented in the absence of reinforcement, which results in the reduction of the conditioned responding over time. Return of fear procedures can be used to further probe competition between previously learned fear and safety associations. For instance, during reinstatement, an unsignalled US typically results in a return of the conditioned responding (for review see Haaker et al., 2014).

Promisingly, a growing body of research has started to assess the role of IU in modulating classical fear conditioning mechanisms during different classical fear conditioning 
procedures (for review see Lonsdorf \& Merz, 2017; Morriss, Wake et al., 2021; Morriss et al., 2021; Sjouwerman et al., 2020). Currently, the findings have been mixed with regards to how IU influences initial learning of fear and safety associations during fear acquisition training (for review see Morriss, Zuj et al., 2021). However, there is clearer evidence demonstrating how high levels of IU disrupt the learning of safe associations during extinction training (i.e. higher IU is associated with greater skin conductance responding to learned fear vs. safe cues during late extinction training) (Morriss et al., 2021). Despite this progress, there remain several nuances that require addressing, in order to form firmer conclusions on the modulatory impact of IU upon fear conditioning mechanisms during fear acquisition and extinction training. This is a prerequisite to facilitate translation of these basic research findings into tailored prevention and intervention approaches.

Firstly, IU-related effects during classical fear conditioning procedures have primarily been examined using self-reported ratings of expectancy and skin conductance response (Morriss, Zuj, et al., 2021). However, only a few studies have examined IU-related effects using self-reported ratings of fear and other psychophysiological measures such as fear potentiation of the startle reflex (Mertens \& Morriss, 2021; Sjouwerman et al., 2020). Importantly, different measures have different temporal profiles and thus capture distinct aspects of how fear and safety signals are processed (e.g., Contantinou et al., 2021; Lipp, 2006; Lonsdorf et al., 2017). Hence, establishing whether IU-related effects are specific to a particular measure or generalise across measures may reveal how IU-related biases modulate classical fear conditioning mechanisms. Secondly, the majority of studies examining IU have focused on immediate extinction training (Dunsmoor et al., 2015; Kanen et al., 2020; Lucas et al., 2018; Morriss, 2019; Morriss et al., 2015, 2016; Morris et al., 2019; Morriss \& van Reekum, 2019; Morriss et al., 2020; Wake et al., 2020; Wake et al., 2021) and we are, to date, not aware of any study that has examined IU during delayed extinction training. Delayed extinction training more closely models the clinical scenario as exposure-based treatment typically occurs with a time delay after exposure to a traumatic or aversive event. While the difference between immediate and delayed extinction training seems subtle, timing of extinction training has been shown to impact how learned fear and safety associations are consolidated (Lonsdorf et al., 2017). For instance, immediate extinction has been shown to increase the return of fear at a later test - which has been referred to as the 'immediate extinction deficit' (Briggs \& Fava, 2016, Huff et al., 2009; Johnson et al., 2010; Maren, 2014; Merz et al., 2016; Woods et al., 2008). As such, 
investigating the modulatory role of IU in a delayed extinction paradigm may clarify the extent of IU-related disruption of safety learning.

To address these gaps in the IU and fear conditioning literature, we re-analyzed a fear conditioning experiment with fear acquisition and delayed extinction training phases. The experiment also had a return of fear (i.e. reinstatement) phase. Yet no hypotheses were formulated for this experimental phase as a mood induction phase preceded it (for transparency results are reported in the Appendix). The study employed multiple, read-out measures (i.e., fear ratings, skin conductance response, auditory-startle reflex) and self-reported traits related to negative emotionality (i.e. the Intolerance of Uncertainty Scale (IUS): Freeston et al., 1994; Trait Anxiety (STAI-T): Spielberger et al., 1983). In the literature, it is well established that IU and STAI-T are positively associated (e.g. Jensen et al., 2016; Sjouwerman et al., 2020) and share common variance (Norr et al., 2013; Sjouwerman et al., 2020) and both questionnaires have been linked to fear conditioning and extinction processes (for a review see Lonsdorf \& Merz, 2017; Sjouwerman et al., 2020; Morriss, Wake, et al., 2021). In order to examine the unique contribution of IU on conditioned responding over and above general negative affect, we included STAI-T primarily as a factor to be controlled for in our analysis. Furthermore, we examined self-reported IU as a single-factor, rather than a multiple-factor (Bottesi et al, 2019; Carleton et al., 2007), because prior research on the impact of IU upon skin conductance responses during immediate extinction training has yielded more consistent results with IU as a single-factor (Morriss, Wake, et al., 2021).

We hypothesised:

(1) IU, controlling for STAI-T, may be associated with skin conductance responding differences to learned fear vs. safety cues during fear acquisition training. Given the mixed literature with empirical evidence indicating both a negative (Sjouwerman et al., 2020) but also a positive relationship (for review see Morriss et al., 2021) between IU and skin conductance responding to learned fear vs. safety cues, a directional hypothesis is not specified.

(2) Higher IU, controlling for STAI-T, will be specifically associated with greater skin conductance responding to learned fear vs. safe cues during delayed extinction training, like prior work of immediate extinction training (Morriss, Wake, et al., 2021; Morriss, Zuj, et al., 2021).

(3) IU, controlling for STAI-T, may be associated with the auditory startle reflex to learned fear vs. safe cues during fear acquisition training and delayed extinction 
training. Due to mixed findings regarding IU and auditory startle reflex during acquisition training indexing a positive (Chin et al., 2016), negative (Sjouwerman et al., 2020), or null results (Mertens \& Morriss, 2021) of IU and auditory startle reflex to learned fear vs. safe cues and the lack of prior literature on IU and auditory startle reflex during extinction training, a directional hypothesis is not specified.

(4) IU, controlling for STAI-T, may be associated with fear ratings to learned fear vs. safe cues during fear acquisition training and delayed extinction training (for review see Morriss, Zuj, et al., 2021). However, given the mixed literature on IU and ratings, where the majority of studies report null results (Morriss, Zuj, et al., 2021; c.f. Morriss, Bell et al., 2021; Sjouwerman et al., 2020), a directional hypothesis is not specified.

\section{Material and methods}

\subsection{Prior use of the data and pre-registration}

The present data were collected as part of an unpublished master's thesis focusing on the impact of experimental mood induction on a retention test and reinstatement. The current investigation constitutes an exploratory study and neither hypotheses nor analysis approaches were pre-registered.

\subsection{Participants}

Participants were recruited via advertisement at the online job portal of the University of Hamburg (stellenwerk.de). Exclusion criteria clarified on the telephone were self-reported current or regular intake of medication (exception: oral contraceptives), substance abuse, neurological, psychiatric or chronic diseases, experienced trauma, age under 18 or over 40 years, and no fluent German language.

Overall, 66 participants ( $\mathrm{n}_{\text {female }}=44, \mathrm{n}_{\text {male }}=22$ aged between 18 and 40 years, $M=$ 25.76, $S D=5.82$, left-handers: $n=3$, retrained right-handers: $n=3$ ) took part in the study. Several participants had to be excluded due to technical issues $(n=3)$, non-responding (SCR: $n$ $=2$; auditory startle blink: $n=1$; for details, see section 2.4 Measurements) and no SCRs to the CSs $(n=1)$. Participants had normal or corrected to normal vision. Nine participants reported 
intake of medication as well as chronic or neurological diseases subsequent to the experiment (see Appendix for details). The decision to keep these participants in the sample was based on the assumption of no impact on results in those cases. All other criteria were fully met.

The study was approved by the Ethics Committee of the General Medical Council (Ärztekammer Hamburg). Participants provided written informed consent in accordance with the Declaration of Helsinki. The financial compensation was 10 Euros per hour.

\subsection{Materials}

Stimuli were presented with Presentation software (Version 14.8, Neurobehavioral Systems, Inc., Albany California, USA).

\subsubsection{Electrotactile stimulus}

The electrotactile stimulus serving as unconditioned stimulus (US) was administered to the back of the right hand of participants and consisted of a train of three $2 \mathrm{~ms}$ electrotactile squarewaves (inter stimulus interval, ISI: $50 \mathrm{~ms}$ ). It was generated by a Digitimer DS7A constant current stimulator (Welwyn Garden City, Hertfortshire, UK) and delivered through a $1 \mathrm{~cm}$ diameter platinum pin surface electrode (Speciality Developments, Bexley, UK) fixed between the metacarpal bones of the index and middle finger. The US was calibrated by using a standardized stepwise procedure aiming at an unpleasant, but still tolerable level rated by the participants between 7 and 8 on a scale ranging from zero to 10 . The identical US intensity was used on both experimental days as calibrated on day 1 .

\subsubsection{Auditory stimulus}

$95 \mathrm{~dB}$ white noise burst (i.e., startle probe) was presented simultaneously on both ears via headphones (Sennheiser, Wedemark, Germany). Startle probes were administered at the beginning of experimental days 1 and 2 to achieve a robust baseline startle reactivity (Blumenthal et al., 2005; i.e., startle habituation), 6 or $8 \mathrm{~s}$ after the ITI-onset, and 6 or $7 \mathrm{~s}$ after 
CS-onset. The different onsets of startle probes were counterbalanced between participants and were intended to avoid predictability (Lonsdorf et al., 2017).

\subsubsection{Visual stimuli: Fear conditioning}

Two different white snow fractals $(80 \times 80 \mathrm{~mm})$ served as CSs and were presented for $8 \mathrm{~s}$ in each experimental phase (except for the affect induction phase, see Appendix for further details) in the center of the screen (Scharfenort et al., 2016; Scharfenort \& Lonsdorf, 2016). One of the two snow fractals, also referred to as CS+, co-occurred with the US, whereas the other one (i.e., the CS-) did never (100\% reinforcement rate). During fear acquisition training, the US was delivered $7.9 \mathrm{~s}$ after CS+ onset and overlapped with the presentation of the CS+ for 100 $\mathrm{ms}$. The order of CS presentations was randomized for each experimental phase, but no more than two identical CSs were in a row. Allocation of the two snow fractals to the CS+ and CS- as well as the order of appearance of CSs (first CS presented $=$ CS + vs. first CS presented $=$ CS - ) were counterbalanced between participants.

A white fixation cross $(8 \times 8 \mathrm{~mm})$ in the center of the screen gray background was presented during startle habituation and inter trial intervals (ITIS), which interleaved the presentations of CSs. The duration of the ITIs ranged from 10 to $13 \mathrm{~s}$ in each experimental phase $(M=11.5)$. All visual stimuli were presented on a gray background (RGB: 100, 100, 100).

\subsection{Measurements}

\subsubsection{Questionnaires}

Intolerance of uncertainty: The Intolerance of Uncertainty Scale (IUS) captures the personal predisposition to experience uncertain future situations as stressful (Freeston et al., 1994). Example aspects of intolerance of uncertainty are expectations concerning the predictability of the future and attempts to control the future. The questionnaire consists of 27 items rated on a 5-point Likert scale (How typical are these statements for you? answer poles: not at all typical for me and entirely typical for me). 
Trait anxiety: Trait anxiety was assessed by applying the State-Trait Anxiety Inventory (Spielberger et al., 1983). The trait scale of this self-assessment method assesses anxiety as a personal trait, which is persistent over time and different situations. High scores indicate a predisposition to react with anxiety in stressful situations. The scale includes 20 self-statements (e.g. "I am happy"). Participants were asked how they feel in general. Answers were given on a 4-point Likert scale with the answer options almost never, sometimes, often, and almost always.

A standardized post-experimental awareness interview (Scharfenort et al., 2016; Scharfenort \& Lonsdorf, 2016) was conducted after acquisition training on day 1. Participants were asked (a) if they knew when they received the electrotactile stimulation and if so, when exactly, (b) if the electrotactile stimulation followed a certain pattern they were asked to explain and (c) if they noticed anything they would like to report. Participants were classified as aware of CS-US contingencies if they reported in one of these questions that the electrotactile stimulation always followed a certain visual stimulus. Otherwise they were classified as unaware. Participants also indicated aversiveness of the US and startle probes on a scale ranging from zero to 100.

\subsubsection{Fear ratings}

Throughout the experiment, participants rated how much stress, fear, and tension they experienced, when they last saw the CS+ and CS-. Ratings to both CSs were provided intermittently (to reduce predictability of a rating block) after 3 to 7 CS presentations as a tradeoff between trial-by-trial ratings and ratings only after each experimental phase: after habituation (i.e., prior to acquisition training), three times during acquisition training and four times during extinction training (with the first rating prior to extinction training). Answers had to be logged in via button press within $7 \mathrm{~s}$ on a visual analog scale (VAS) ranging from zero (answer = none) to 100 (answer $=$ maximum). Unlogged ratings were considered as missing values. 


\subsubsection{Physiological measures}

Physiological measures were recorded using a BIOPAC MP 100 amplifier and fed into AcqKnowledge software (Version 3.9.1.6, BIOPAC Systems, Inc., Goleta, California, USA). Data were recorded with a $1000 \mathrm{~Hz}$ sampling rate, a gain of $5 \mu \Omega / N$ and a $1.0 \mathrm{~Hz}$ hardware filter.

\subsubsection{SCR}

For measuring SCRs, two self-adhesive, with hydrogel and $\mathrm{Ag} / \mathrm{AgCl}$-sensor recording SCR electrodes $(\varnothing=55 \mathrm{~mm})$ were attached on the palm of the left hand, i.e., on the distal and proximal hypothenar. A $1 \mathrm{~Hz}$ lowpass filter and a gain of $5 \mu \Omega$ were applied. For $n=3$ participants a gain of $10 \mu \Omega$ was applied due to the participants' higher response range. SCR data were scored by using the semi-automatic scoring system Autonomate (Green et al., 2014). Within Autonomate, data were down sampled to $10 \mathrm{~Hz}$. According to published guidelines (Boucsein et al., 2012), the onset of the first response within 0.9 to $4 \mathrm{~s}$ after onset of CSs was scored as SCR from trough to peak (for US: the first response within 0.7 to $4 \mathrm{~s}$ after onset of US) with a maximum rise time of $5 \mathrm{~s}$ (i.e., first interval response, Grings et al., 1962). SCRs under $0.02 \mu \mathrm{S}$, or an absence of it within the defined time window were classified as a zeroresponses. Data with recording artifacts or excessive baseline activity were treated as missing data points. Within Autonomate, each scored SCR was checked visually, and the scoring was corrected, if necessary.

SCR's were square root transformed to reduce skewness. Then, SCR's were z-scored within individuals across trials for day 1 and day 2 separately to control for interindividual differences in skin conductance responsiveness not due to the experimental manipulation (BenShakhar, 1985; Lonsdorf et al., 2019).

Participants were considered SCR non-responders if they had more than two thirds of zero responses to the US on day 1 or all zero responses to the US during reinstatement on day 2 (as recommended by Lonsdorf et al., 2019).

For the SCR data, 3 participants were excluded from day 1 analyses (1 due to stimulus marker error; 2 due to no responses to the CS, subsequently resulting in no z-scored values) and 2 participants were excluded from day 2 analyses ( 1 non-responder; 1 due to no responses 
to the CS, subsequently resulting in no z-scored values). This left 61 participants for day 1 and 62 participants for day 2 analyses of SCR data.

\subsubsection{Auditory startle blink}

For electromyography (EMG) startle, two $\mathrm{Ag} / \mathrm{AgCl} \mathrm{EMG}$ electrodes were placed over the orbicularis oculi muscle: one electrode was attached as close as possible under the lower lash line in the middle of the pupil of the right eye and the second one was positioned directly to the left of the first electrode. The reference electrode was placed in the middle of the forehead. During data acquisition, a gain of 5000 at $1000 \mathrm{~Hz}$ and a band-pass filter $(28-500 \mathrm{~Hz})$ were applied. Data were rectified and integrated online (averaged over 20 samples). Startle data were scored semi-automatically by using a custom-made computer program (EDA View, developed by Prof. Dr. Matthias Gamer, University of Würzburg). According to the published recommendations by Blumenthal et al. (2005), startle responses occurring 20-120 ms after the startle probe onset were scored as trough to peak. Measurements with recording artifacts or excessive baseline activity as well as spontaneous blinks occurring $50 \mathrm{~ms}$ prior to startle probes were treated as missing data points. The absence of a response within the defined time window was classified as a zero-response. Auditory startle blink was z-scored within individuals across trials for day 1 and day 2 separately.

Participants were considered auditory startle blink non-responders if they had more than one third of zero responses and/or missing data points.

For startle blink, 2 participants were excluded for day 1 analyses ( 1 due to stimulus marker error; 1 non-responder) and 1 participant for day 2 analyses (1 non-responder). This left 62 participants for day 1 and 63 participants for day 2 analyses of startle data. 


\subsection{Procedure}

The study was conducted on three separate days. Assessments on day 1 and day 2 (see Figure 1) took place in one of two different psychophysiological laboratories (the same participant was, however, examined in the same laboratory on both days) of the University Medical Center Hamburg-Eppendorf (UKE). On day 3, the participants filled in an online battery of questionnaires by using the survey tool LimeSurvey (LimeSurvey GmbH, Hamburg, Germany, http://www.limesurvey.org).

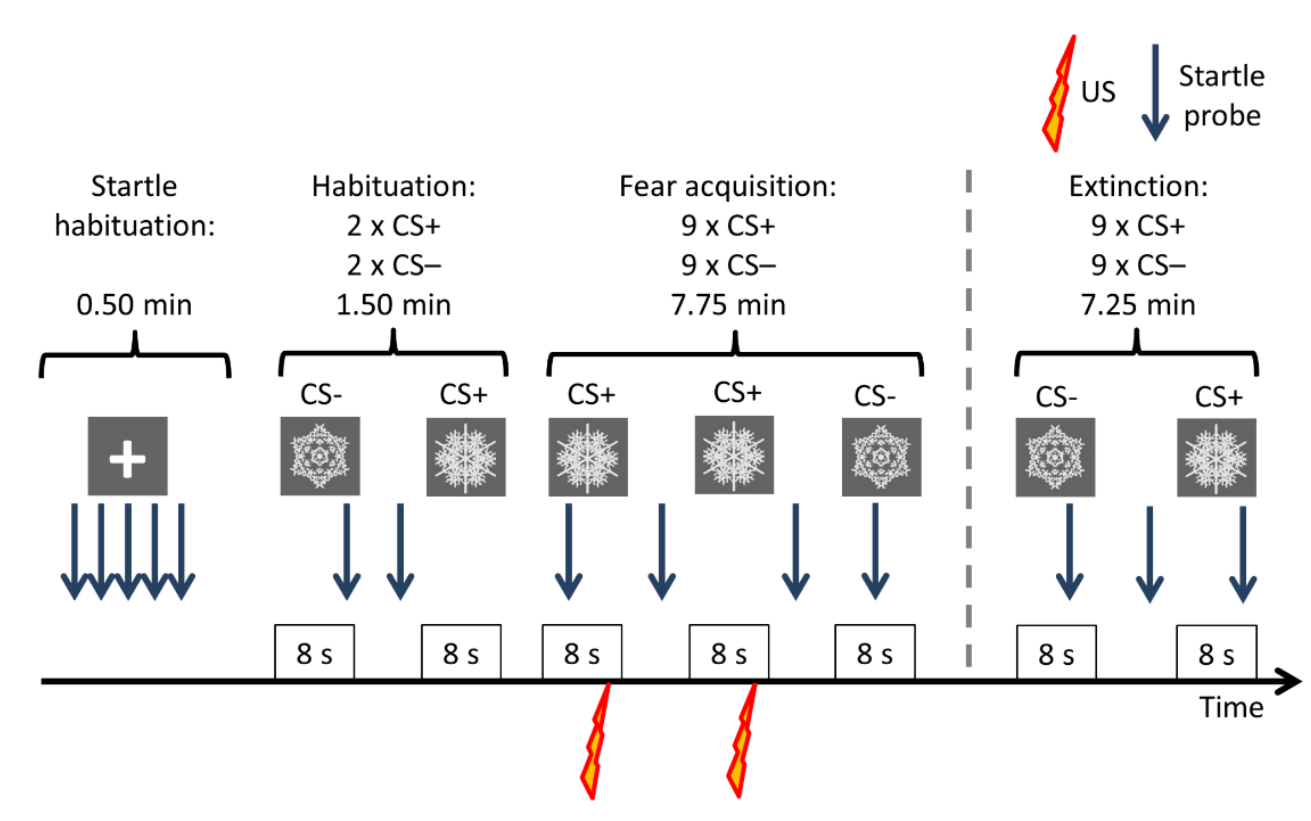

Figure 1. Image depicting procedure for fear acquisition training and delayed extinction training.

On day 1 , the experimental procedure was identical for all participants. Participants were not informed about CS-US-contingencies prior to the experiment.

During startle habituation, five startle probes were presented on a white fixation cross interleaved with 6-s ISIs. Both CSs were presented prior to the fear acquisition training to avoid orienting responses (habituation). Half of the CS presentations and ITIs were startled during habituation. Participants were informed that there was no presentation of the US during startle habituation and habituation. Subjective fear ratings of both CSs and an unpleasantness rating of the startle probes using the same procedure as for fear ratings (see section 2.4 Measurements) followed after the habituation phase. 
During fear acquisition training, 2/3 of the CS presentations were startled. Startle probes were also presented in $1 / 3$ of ITIs during this and all following phases. Subjective fear ratings had to be completed intermittently. After fear acquisition training, participants had to indicate the unpleasantness of the startle probes and the US.

Twenty-four hours after fear acquisition training, participants returned to the laboratory $( \pm$ max. $2.75 \mathrm{hrs}$ ). Again, the experiment started with the delivery of five startle probes as startle habituation (not shown in Figure 1). Afterwards, participants had to indicate the unpleasantness of the startle probes by using the same procedure as for fear ratings. During extinction training, no US was presented. Two thirds of the CS presentations were startled and subjective fear ratings were presented intermittently.

The extinction training was immediately followed by an affect induction (negative vs. neutral slides were presented), a short re-extinction training, reinstatement and a reinstatementtest phase (see Appendix for further details).

\subsection{Analyses}

Statistical analyses were conducted using the mixed procedure in SPSS 24.0 (SPSS, Inc; Chicago, Illinois). We conducted separate MLMs for the fear ratings, SCR and auditory startle blink during i) fear acquisition training and ii) delayed extinction training. For all MLMs we entered Stimulus (CS+, CS-) and Trial (number of trials varied by phase and measure) at level 1 and individual subjects at level 2. We included demeaned (i.e. subtracting the sample mean from each observation so that they are mean zero) IUS and STAI-T scores as continuous individual difference predictor variables in the MLMs separately. In all models, we used a diagonal covariance matrix for level 1. Random effects included a random intercept for each individual subject, where a variance components covariance structure was used. We used a maximum likelihood estimator for the MLMs.

If a significant Stimulus $\mathrm{x}$ IUS or Stimulus $\mathrm{x}$ STAI-T interaction was observed from a MLM, we assessed specificity by conducting a further MLM with both IUS and STAI-T included. In line with past research (Mertens \& Morriss, 2021; Morriss et al., In Press), to further understand Stimulus $x$ IUS/STAI-T interactions from the MLMs, we conducted correlations (two- 
tailed) between the relevant self-report measure (i.e. IUS/STAI-T) and each condition separately (i.e. CS+, CS-) and as a difference score (i.e. CS+ - CS-).

To assure robustness of results, associations between IUS as well as STAI-T scores and CS-US contingency awareness of participants, US intensity, reported US and startle probe aversiveness on both experimental days and mean SCRs to the US during acquisition training were investigated by comparing IUS and STAI-T scores between aware and unaware participants with independent sample t-tests and calculating Pearson correlation coefficients for IUS as well STAI-T scores and the aforementioned variables. Results of these robustness analyses are briefly described below and in more detail in the Appendix. For assessments of US and startle probe aversiveness, values as retrieved from the post-experimental awareness interview were taken into account as some of the aversiveness ratings that were completed after the experiment were missing.

We conducted a sensitivity analysis based on a point biserial correlation model, in line with our follow up correlational tests between IUS as well as STAI-T scores and CS+, CS- and the difference score (CS+ - CS-). Based on our largest (two tailed, $\alpha=0.05,1-\beta$ err prob $=0.8$, $n=64$ ) and smallest (two tailed, $\alpha=0.05,1-\beta$ err prob $=0.8, n=61$ ) sample size, the effect sizes that we were able to detect in the current study was 0.33 and 0.34 respectively. This small-medium effect size is comparable to that reported in a recent meta-analysis of correlational data between IUS scores and skin conductance responding during threat extinction learning (Morriss, Wake et al., 2021). Note that this is not the observed power.

\section{Results}

MLM statistics for Stimulus, Trial and interactions between Stimulus $\times$ Trial are presented in the text. Interactions between Stimulus $x$ Trial will not be followed up, as they are beyond the scope of the manuscript.

Furthermore, MLM statistics for Stimulus x IUS/STAI-T interactions are also presented in the text and in Table 1. MLM statistics for main effects of STAI-T and IUS, as well as interactions between Trial $x$ IUS/STAI-T and Stimulus $x$ Trial $x$ IUS/STAI-T are presented in Table 1 for transparency but are not presented in the text. Follow up tests such as MLMs with 
both IUS/STAI-T included and correlations between conditions and IUS/STAI-T are presented in the text only.

\subsection{Questionnaires}

Cronbach's alphas for IUS and STAI-T were .91 (95\% confidence interval [CI]: .87, .94) and .92 $(95 \% \mathrm{Cl}: .89, .95)$ respectively. IUS was positively significantly correlated with STAI-T $[r(62)=$ $.559, p<.001]$. IUS and STAI-T scores were normally distributed and typical for a community sample [IUS: $M=64.67, S D=16.91$, range $=33$ - 109; STAI-T: $M=39.07 ; S D=9.73$, range = 24 - 73; see Figure 2].
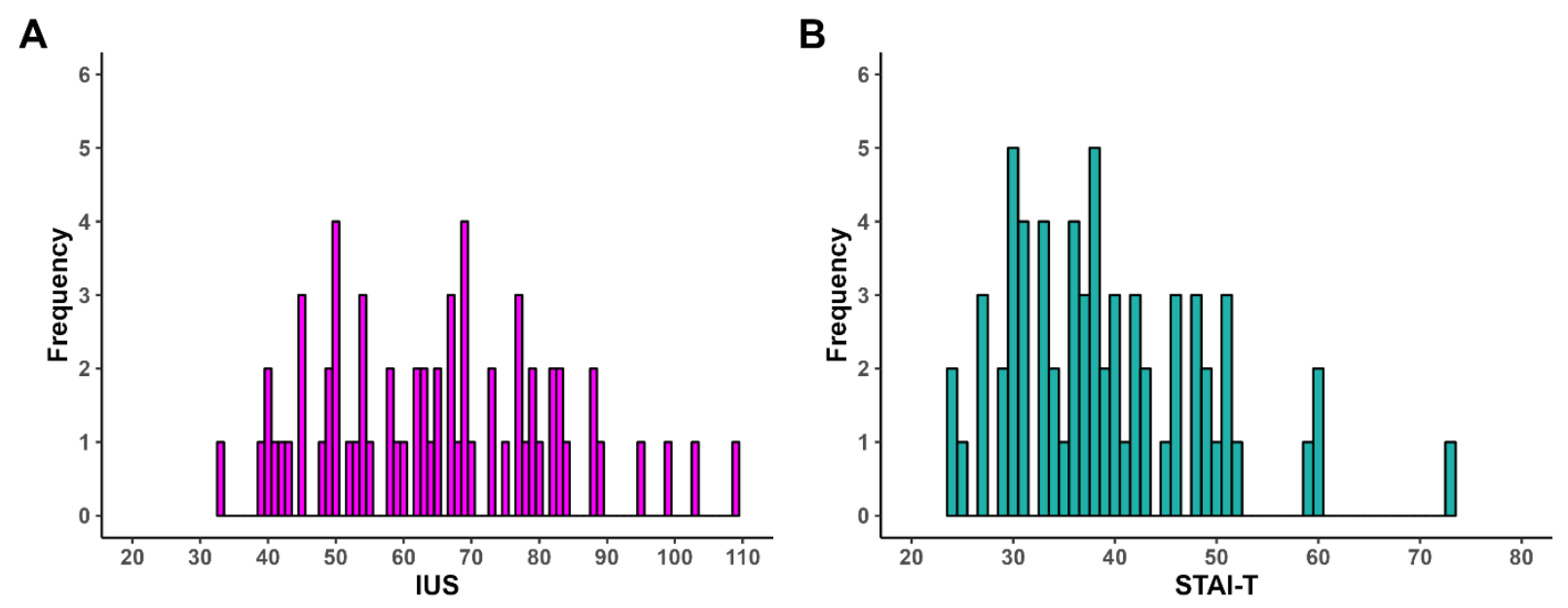

Figure 2. Histograms of IUS (A) and STAI-T (B) scores. 
Table 1. IUS and STAI-T interactions from MLMs per phase and measure

\begin{tabular}{|c|c|c|c|c|c|c|}
\hline & \multicolumn{3}{|c|}{ Fear Acquisition Training } & \multicolumn{3}{|c|}{ Delayed Extinction Training } \\
\hline & Fear ratings & SCR magnitude & Auditory startle blink & Fear ratings & SCR magnitude & Auditory startle blink \\
\hline IUS & $\begin{array}{l}F(1,65.219)=5.427, \\
p=.023\end{array}$ & $\begin{array}{l}F(1,222.099)=.232 \\
p=.630\end{array}$ & $\begin{array}{l}F(1,680.305)=.134 \\
p=.714\end{array}$ & $\begin{array}{l}F(1,65.485)=.105 \\
p=.746\end{array}$ & $\begin{array}{l}F(1,79.962)=.814 \\
p=.370\end{array}$ & $\begin{array}{l}\mathrm{F}(1,653.070)=1.426 \\
\mathrm{p}=.233\end{array}$ \\
\hline STAI-T & $\begin{array}{l}F(1,65.530)=8.990 \\
p=.004\end{array}$ & $\begin{array}{l}\mathrm{F}(1,226.459)=.422 \\
\mathrm{p}=.517\end{array}$ & $\begin{array}{l}\mathrm{F}(1,681.875)=.020 \\
\mathrm{p}=.888\end{array}$ & $\begin{array}{l}F(1,65.716)=.000 \\
p=.986\end{array}$ & $\begin{array}{l}F(1,82.537)=.000 \\
p=.995\end{array}$ & $\begin{array}{l}\mathrm{F}(1,653.162)=1.156 \\
\mathrm{p}=.283\end{array}$ \\
\hline $\begin{array}{l}\text { Stimulus } \mathrm{x} \\
\text { IUS }\end{array}$ & $\begin{array}{l}F(1,378.184)=4.093 \\
p=.044\end{array}$ & $\begin{array}{l}\mathrm{F}(1,222.099)=.806 \\
\mathrm{p}=.370\end{array}$ & $\begin{array}{l}F(1,680.305)=.130 \\
p=.719\end{array}$ & $\begin{array}{l}F(1,327.884)=7.873 \\
p=.005\end{array}$ & $\begin{array}{l}F(1,917.188)=.277 \\
p=.599\end{array}$ & $\begin{array}{l}F(1,653.070)=.029 \\
p=.864\end{array}$ \\
\hline $\begin{array}{l}\text { Stimulus } x \\
\text { STAI-T }\end{array}$ & $\begin{array}{l}F(1,373.124)=.138 \\
p=.710\end{array}$ & $\begin{array}{l}F(1,226.459)=2.356 \\
p=.126\end{array}$ & $\begin{array}{l}\mathrm{F}(1,681.875)=.730 \\
\mathrm{p}=.393\end{array}$ & $\begin{array}{l}F(1,305.878)=3.950 \\
p=.048\end{array}$ & $\begin{array}{l}F(1,910.598)=1.825 \\
p=.177\end{array}$ & $\begin{array}{l}\mathrm{F}(1,653.162)=.001 \\
\mathrm{p}=.979\end{array}$ \\
\hline Trial $\times$ IUS & $\begin{array}{l}F(3,172.134)=2.347 \\
p=.074\end{array}$ & $\begin{array}{l}F(8,229.004)=2.084 \\
p=.038\end{array}$ & $\begin{array}{l}F(5,225.299)=.242 \\
p=.943\end{array}$ & $\begin{array}{l}F(3,197.047)=4.104 \\
p=.007\end{array}$ & $\begin{array}{l}F(8,216.644)=.798 \\
p=.605\end{array}$ & $\begin{array}{l}\mathrm{F}(5,235.958)=.504 \\
\mathrm{p}=.773\end{array}$ \\
\hline $\begin{array}{l}\text { Trial } x \\
\text { STAI-T }\end{array}$ & $\begin{array}{l}F(3,171.955)=.749 \\
p=.525\end{array}$ & $\begin{array}{l}F(8,241.561)=1.358 \\
p=.216\end{array}$ & $\begin{array}{l}F(5,254.296)=3.416 \\
p=.005\end{array}$ & $\begin{array}{l}F(3,202.087)=5.686 \\
p=.001\end{array}$ & $\begin{array}{l}F(8,214.683)=2.295, \\
p=.022\end{array}$ & $\begin{array}{l}F(5,217.273)=.478 \\
p=.792\end{array}$ \\
\hline $\begin{array}{l}\text { Stimulus } \mathrm{x} \\
\text { Trial } \mathrm{x} \text { IUS }\end{array}$ & $\begin{array}{l}F(3,172.255)=.301 \\
p=.825\end{array}$ & $\begin{array}{l}F(8,229.004)=1.083 \\
p=.376\end{array}$ & $\begin{array}{l}F(5,225.299)=2.056 \\
p=.072\end{array}$ & $\begin{array}{l}\mathrm{F}(3,197.047)=.944 \\
\mathrm{p}=.421\end{array}$ & $\begin{array}{l}F(8,216.644)=.599 \\
p=.779\end{array}$ & $\begin{array}{l}F(5,235.958)=.474 \\
p=.796\end{array}$ \\
\hline $\begin{array}{l}\text { Stimulus } x \\
\text { Trial } x \\
\text { STAI-T }\end{array}$ & $\begin{array}{l}F(3,172.011)=.287 \\
p=.835\end{array}$ & $\begin{array}{l}F(8,241.561)=1.240 \\
p=.276\end{array}$ & $\begin{array}{l}F(5,254.296)=.444 \\
p=.817\end{array}$ & $\begin{array}{l}F(3,202.087)=.256 \\
p=.857\end{array}$ & $\begin{array}{l}F(8,214.682)=.645 \\
p=.739\end{array}$ & $\begin{array}{l}F(5,217.273)=.113 \\
p=.989\end{array}$ \\
\hline
\end{tabular}

Note. MLM statistics for Stimulus $\mathrm{x}$ IUS/STAI-T interactions are also presented in the text. MLM statistics for main effects of STAI-T and IUS, as well as interactions between Trial $x$ IUS/STAI-T and Stimulus $x$ Trial $x$ IUS/STAI-T are presented in this table for transparency but are not presented in the text. When both STAI-T and IUS were entered into the model, the main effect of STAI-T remained $[F(1,65.114)=4.092, p=$ .047], whereas the main effect of IUS was not significant anymore $[F(1,65.296)=.775, p=.382]$. A follow up correlational test showed that higher STAI-T was associated with greater fear ratings during fear acquisition training $[r(62)=.346, p=.005]$. Entries in the table that are formatted in bold indicate significance. Grey font denotes that the effect was not significant when controlling for IUS or STAI-T. 


\subsection{Fear acquisition training}

Fear ratings: Larger fear ratings were observed for $\mathrm{CS}_{+}$, compared to the CS- [Stimulus, $F(1$, $380.052)=83.742, p<.001]$. Fear ratings generally increased across trials, however, this effect was more pronounced for the CS+, relative to the CS- [Trial, $F(3,173.647)=31.751, p<.001$; Stimulus $x$ Trial, $F(3,173.742)=14.453, p<.001$; see Figure 3]. 

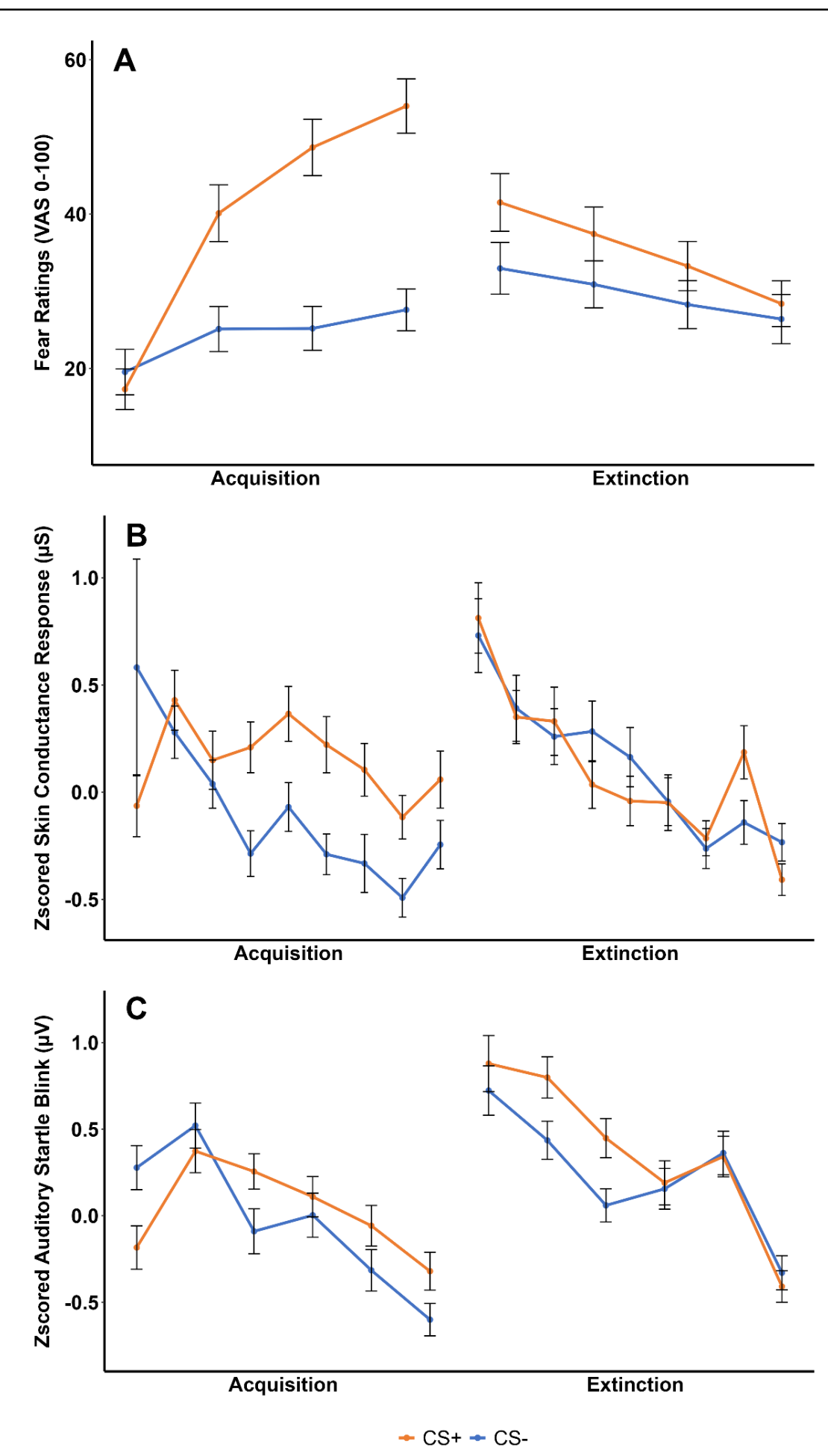

Figure 3. Single trial data during fear acquisition training and delayed extinction training for fear ratings (A), SCR (B) and auditory startle blink (C). SCR and auditory startle blink data were zscored. Data represent \pm standard error of the mean. 
A IUS $x$ Stimulus interaction emerged, both when IUS was entered into the model alone $[p=.044$, see Table 1] and when entered with the STAI-T $[F(1,379.376)=7.476, p=.007]$. Follow up correlational tests suggested that higher IUS was significantly positively associated with greater fear ratings to the $C S+[r(62)=.309, p=.013]$. IUS was not significantly associated with fear ratings to the CS- $[r(62)=.160, p=.205]$. However, the difference between these two correlations was not significant $[z=1.3, p=.19]$. IUS was also not significantly correlated with the CS+ - CS- difference score $[r(62)=.172, p=.174]$ (see Figure 4).

For fear ratings during fear acquisition training, no significant interactions between Stimulus x STAI-T emerged (see Table 1).

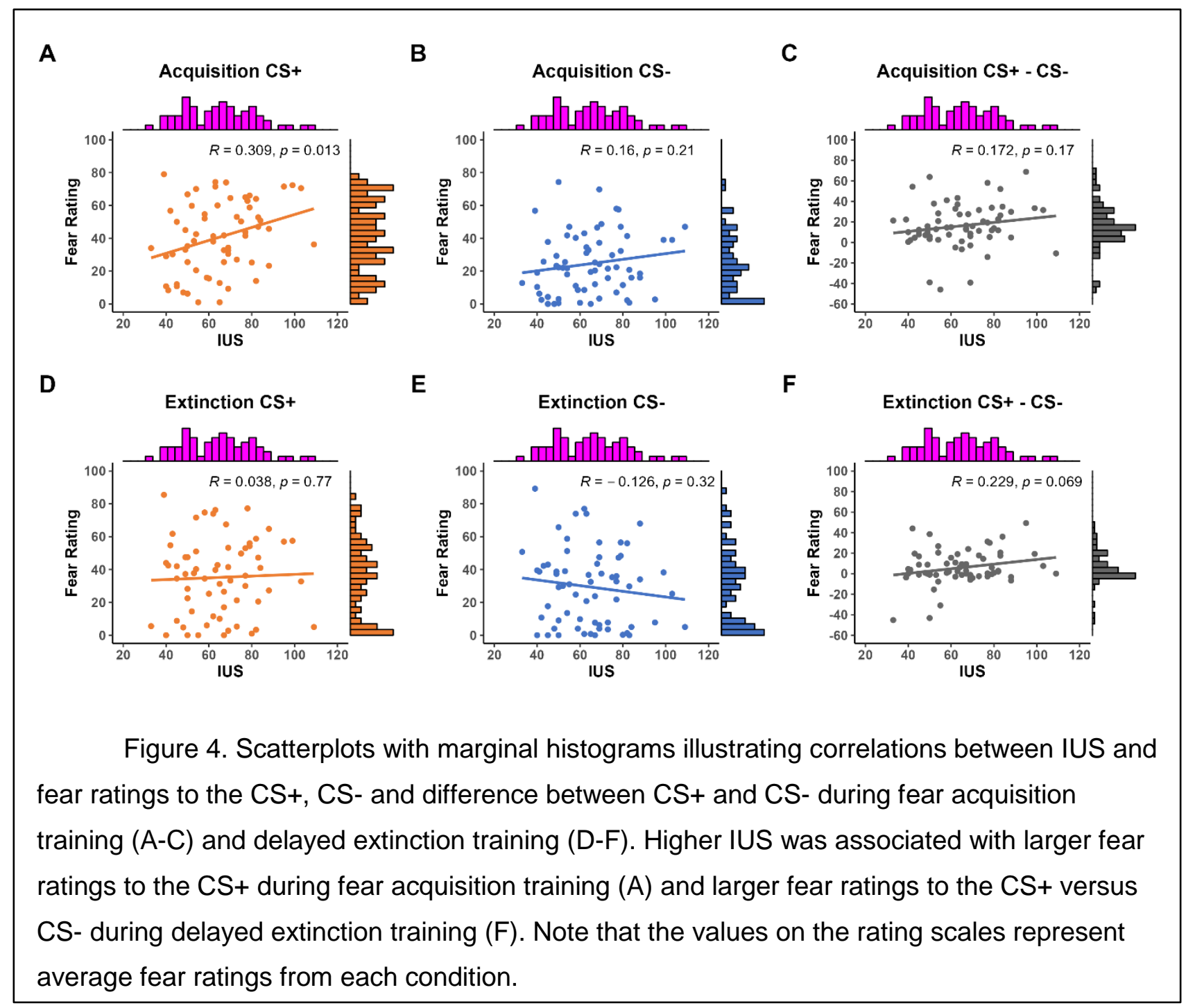


SCR: The CS+ elicited larger SCRs, compared to the CS- [Stimulus, $F(1,221.706)=9.703, p=$ .002; see Figure 3]. SCR habituated across trials [Trial, $F(8,230.262)=5.907, p<.001$ ]. No significant interaction for Stimulus $\times$ Trial was observed [Stimulus $\times$ Trial, $F(8,230.262)=1.189$, $p=.306]$. For SCR, no significant interactions between Stimulus $\times$ IUS or Stimulus $\times$ STAI-T were found (see Table 1).

Startle: For startle, no significant main effect Stimulus was found [Stimulus, $F(1,676.791)=$ $.908, p=.341]$. However, there was some evidence of conditioning on startle across trials [Stimulus $x$ Trial, $F(5,228.889)=3.427, p=.005$; see Figure 3]. Startle responses habituated across trials [Trial, $F(5,228.889)=14.797, p<.001]$. For startle, no significant interactions between Stimulus $x$ IUS or Stimulus x STAI-T emerged (see Table 1).

\subsection{Delayed extinction training}

Fear ratings: Larger fear ratings were observed for CS+, compared to the CS- [Stimulus, $F(1$, $323.631)=18.739, p<.001$; see Figure 3]. Fear ratings decreased across trials [Trial, $F(3$, $195.409)=10.184, p<.001]$. No significant interaction for Stimulus $x$ Trial was observed [Stimulus $x$ Trial, $F(3,195.409)=1.198, p=.312$ ].

A Stimulus $x$ IUS interaction was observed when IUS was entered into the model alone [ $p=.005$, see Table 1] and with STAI-T $[F(1,325.890)=4.344, p=.038]$. Follow up correlational tests suggested that higher IUS was positively associated with greater differential fear ratings to the CS+ vs. CS- at trend [ $r(62)=.229, p=.069]$. IUS was not significantly associated with fear ratings to the CS+ $[r(62)=.038, p=.766]$ or CS- $[r(62)=-.126, p=.322]$ (see Figure 4).

Similarly, when including STAI-T alone in the model, a Stimulus $x$ STAI interaction was observed [ $p=.048$, see Table 1], however, this effect was non-significant when both STAI-T and IUS were entered into the model $[F(1,315.651)=.273, p=.602]$.

SCR: For SCR, no effect of stimulus type was found during delayed extinction training [Stimulus, $F(1,909.504)=.104, p=.747$; see Figure 3]. SCR habituated across trials [Trial, $F(8$, $214.470)=15.068, p<.001]$. No significant interaction for Stimulus $x$ Trial was observed 
[Stimulus $x$ Trial, $F(8,214.471)=1.296, p=.247]$. For SCR, no significant interactions between Stimulus $\mathrm{x}$ IUS or Stimulus $\mathrm{x}$ STAI-T were found (see Table 1).

Startle: Stronger startle responses were elicited by the CS+, compared to the CS- during delayed extinction training [Stimulus, $F(1,652.248)=4.220, p=.040$; see Figure 3]. Startle habituated across trials [Trial, $F(5,221.341)=27.520, p<.001$ ]. No significant interaction for Stimulus $x$ Trial was found [Stimulus $\times$ Trial, $F(5,221.341)=1.699, p=.136$ ]. For startle, no significant interactions between Stimulus $\mathrm{x}$ IUS or Stimulus $\mathrm{x}$ STAI-T were observed (see Table 1).

\subsection{Robustness analyses}

IUS and STAI-T scores of participants were not associated with awareness of CS-US contingencies, intensity or reported aversiveness of the US, aversiveness of the startle probes or SCRs to the US during acquisition training (see Appendix for details).

Nine participants were not naïve to the experimental setup. Excluding them from the analyses did not change the results substantially (results not shown).

\section{Discussion}

In the present exploratory study, we examined the impact of self-reported IU and STAI-T on fear ratings, skin conductance response and auditory startle blink during fear acquisition and delayed extinction. Self-reported IU, controlling for STAI-T, was associated with fear ratings (i.e. Stimulus $\mathrm{x}$ IUS interaction) during fear acquisition training and delayed extinction training. However, we did not observe a relationship of both IU and STAI-T with conditioned skin conductance or auditory startle blink during fear acquisition and delayed extinction. These results add to and extend our current understanding of the role of IU on subjective and physiological measures during different fear conditioning procedures, particularly with respect to subjectively experienced and reported fearfulness during a threatening situation such as during acquisition and delayed extinction training. 
Typical conditioning was observed across participants during fear acquisition training, indexed by larger fear ratings, skin conductance and auditory startle blink responses to the fear versus safety cues. Furthermore, there was evidence of a reduction of the conditioned response across participants during delayed extinction training, indexed by larger fear ratings and auditory startle blink to the fear versus safety cues that decreased over time while no discrimination or stimulus-specific general habituation was observed for SCRs during delayed extinction training.

During both fear acquisition training as well as delayed extinction training a significant interaction between stimulus and IU was observed that remained significant when controlling for the STAI-T. More precisely, follow-up tests suggest that during acquisition training, higher IU might be associated with significantly greater fear ratings to the $\mathrm{CS}+$ (note, however, that this effect was non-significant for the CS- but both associations did not differ significantly) while during extinction training higher IU was linked to non-significantly larger CS discrimination. In relation to the broader literature, a number of prior studies have reported relationships between IU and fear / valence ratings during fear acquisition training (Morriss, Bell et al., 2021; Sjouwerman et al., 2020). For instance, higher IU, (controlling for STAI-T) was associated with greater ratings of negative valence to learned fear versus safe cues (CS discrimination) during instructed fear acquisition training (Morriss, Bell, et al., 2021). Another study also found higher IU to be associated with greater fear ratings to the CS- during fear acquisition training, a finding that was not specific to IU and was also observed for other measures of self-reported negative emotionality (Sjouwerman et al., 2020).

In addition to the interaction effect of IU and stimulus on fear ratings during acquisition training, we observed a main effect of STAI-T on fear ratings during fear acquisition training which persisted after controlling for IU whereas the main effect of IU did not survive controlling for STAI-T. We suggest that STAI-T scores might affect subjective evaluations of fearfulness more generally, while IU may be more specifically associated with responses to the learned fear cue.

Effects of IU on fear ratings during immediate or delayed extinction training have - as far as we are aware - not been investigated to date. While in the same direction and at trend (significant for the MLM but non-significant for the follow up correlation), the finding that higher IU is associated with greater fear ratings to the learned fear versus safe cue during delayed extinction training is in line with previous literature demonstrating higher IU is associated with greater neural and psychophysiological activity to learned fear versus safe cues during 
immediate extinction training (Morriss et al., 2015; Morriss, 2019; Wake et al., 2021). Notably, the majority of past fear conditioning research on IU has focused on ratings of uneasiness (Morriss et al, 2015; 2016) and expectancy (for review see Morriss et al., 2021), and have reported little effect of IU upon these types of rating measures during fear acquisition and extinction training procedures. Taken together, the findings from this study and the broader literature call for further examination and replication of IU and subjective fear (i.e. described as fear, stress and tension) during fear conditioning procedures.

Null results were observed for IU and psychophysiological measures during fear acquisition. A few studies have reported IU-related effects on skin conductance during fear acquisition with continuous reinforcement (Sjouwerman et al., 2020) and fear acquisition with partial reinforcement and generalisation stimuli (Bauer et al., 2020; Morriss, Macdonald et al., 2016). However, the majority of past research has reported null results for IU and skin conductance during fear acquisition (for review see Morriss, Zuj, et al., 2021). Interestingly, only a few studies have examined the relationship between IU and auditory startle blink during fear acquisition training (Chin et al., 2016; Mertens \& Morriss, 2021; Sjouwerman et al., 2020). The results for IU and startle are mixed. For instance, one study reported greater startle to the learned fear versus safe cues during fear acquisition with partial reinforcement (Chin et al., 2016), another study reported greater startle to the learned safe cue during fear acquisition with continuous reinforcement (Sjouwerman et al., 2020) and another study reported a null result for startle during fear acquisition with partial reinforcement (Mertens \& Morriss, 2021). The lack of cohesion for IU-related findings on skin conductance response and auditory startle blink during fear acquisition training may be due to the different parameters of uncertainty embedded within this phase. For example, the reinforcement rate of the unconditioned stimulus (i.e. partial versus continuous) and the extent to which startle probes are presented (i.e. on some CS trials or on every CS trial; at the same time on the CS trials or at different times on the CS trials) - which have been shown to impact on conditioned responding and fear learning (Sjouwerman et al, 2016). Similarly, we found null results for both IU and STAI-T on psychophysiological measures during delayed extinction training. The null result relating to IU on skin conductance responding during delayed extinction training in this study is rather surprising, given that prior research has demonstrated a relatively robust effect of IU on skin conductance response during immediate extinction training (Morriss, Wake et al., 2021). It is difficult to interpret the null result for IU on auditory startle blink during delayed extinction training because of the scarcity of prior research 
examining IU and auditory startle blink during this phase, or generally across classic fear conditioning procedures (Chin et al., 2016; Mertens \& Morriss, 2021; Sjouwerman et al., 2020).

There may be several reasons for the discrepancy in findings for psychophysiological measures between previous research on IU and immediate extinction training and the current study on IU and delayed extinction training. Firstly, we might not have had enough power to detect an effect that is likely subject to variations due to different samples. In fact, even when there is a true effect, it is common that this effect is not observed consistently in particular in rather small samples as often employed in the field (Schimmack, 2012). Secondly, individuals with high IU may be more prone to uncertainty-induced arousal during immediate extinction training, rather than delayed extinction training because the contingency changes are recent and thus there is greater uncertainty (and potentially competition) between fear and safety associations. Thirdly, the null results for IU on psychophysiological measures during delayed extinction training may be due to a methodological difference. More specifically, a recent metaanalysis (Morriss, Wake, et al., 2021) highlighted that IU-related differences on skin conductance response were observed during the late part of extinction training (i.e. defined as the last 6-10 trials per CS type in studies with over 24 trials in total). The current experiment included 9 trials per CS type and 18 trials overall. Despite the similar length of time for the extinction training phase, the smaller number of trials may reduce the variance needed to capture an IU-related effect on psychophysiological measures. Finally, random variation in the effect is always a possibility that needs to be considered (Schimmack, 2012).

Finally, our results suggest that IU may be more strongly associated with conditioned responding and extinction than the general emotional negativity as assessed through the STAIT. While both are strongly related, it remains a matter of debate to what extent they capture distinct sub-constructs. While we highlight that the results we present here should be considered exploratory and hypothesis generating, we speculate that uncertainty may have a stronger impact than general negative emotionality. However, we note, that the literature on specificity with respect to IU and STAI on conditioned responding is quite mixed (Sjouwerman et al., 2020, Lonsdorf \& Merz, 2017) and call for caution in not overinterpreting these results. In fact, random variation may result in a stronger effect of one of these measures in one study and a weaker effect in another study.

The current study has a number of strengths. Firstly, to our knowledge, the present study is the one of the first that has explored IU during delayed extinction training. The 
application of a two-day-paradigm with fear acquisition and extinction training on two consecutive days is thought to increase ecological validity as it allows the fear memory to consolidate before extinction training (for discussion see, Maren, 2014). Thus, it is assumed to provide a more naturalistic model for the emergence and treatment of anxiety disorders as compared to protocols comprising immediate extinction training (Haaker et al., 2014; Lonsdorf et al., 2017). As these first results we present here have to be considered exploratory, we suggest future research may directly compare immediate and delayed extinction protocols with respect to IU. Secondly, we included subjective and psychophysiological measures in our study and therefore captured different aspects of how fear and safety cues are processed, as recommended by Lonsdorf et al. (2017). To date, only a few studies on IU have measured selfreported fear ratings and auditory startle blink. Here, the observed IU-related effects on fear ratings may be related to the use of a wider rating scale (range of VAS: 0 - 100) as compared to narrower rating scales from previous research (e.g. range: 1-9; Morriss et al., 2015, 2016), which may be more optimal for capturing individual differences in allowing for more variability (Lonsdorf \& Merz, 2017).

However, several restrictions of our study should also be noted. Firstly, we did not include an additional group in our study which underwent an immediate extinction training as this was not in the scope of our work. To further elucidate whether IU impacts immediate and delayed extinction training differently, future research should directly compare immediate and delayed extinction training groups. Secondly, we excluded participants with prior psychiatric history. This might have limited a) the upper range of IUS und STAI-T scores, which are notably higher in clinical samples (McEvoy et al., 2019) and b) the variability in physiological measurements as participants with a history of psychiatric disorders may be more sensitive to those measures - both resulting in a restriction of variance and possibly limiting the chance to detect significant effects. Thirdly, we used a continuous reinforcement rate during fear acquisition training resulting in a rather strong experimental situation and therefore lessening potential uncertainty in the experiment (Lissek et al., 2006). On the other hand, we applied an uninstructed fear acquisition training which might also enhance uncertainty. Future studies could examine whether different reinforcement rates and instruction types contribute to the extent to which IU impacts immediate and delayed extinction training. The research opportunities for examining IU-related effects on conditioned responding in various outcome measures and experimental designs are far from exhausted. 


\section{Conclusion}

IU was related to fear ratings during fear acquisition training and extinction training (less clearly, however), but was observed to be mostly unrelated to psychophysiological responses (i.e., SCR and auditory startle blink). Implementing fear ratings instead or in addition to the previously often employed ratings of uneasiness and expectancy might be a promising future approach to further elucidate associations of IU with self-reports related to fear and investigate whether there is a specific association with subjectively reported fear and IU. Notably, as our work has to be considered exploratory and hypotheses-generating, further research on IUeffects in delayed extinction training might add on these initial findings and may broaden our understanding on how individual differences impact fear related processes in this more clinically relevant model. Ultimately, these insights may in the long-run contribute to improving treatments addressing anxiety and fear related psychopathology and help to secure long-term remission.

\section{Conflict of Interest}

The authors declare no competing financial interests.

\section{Acknowledgements}

This work was supported by grants awarded by the German Research Foundation to TBL (DFG LO1980/1-1).

\section{Author Contributions}

The authors made the following contributions. Maren Klingelhöfer-Jens: Conceptualization, Methodology, Investigation, Data Curation, Visualisation, Writing - Original Draft; Jayne Morriss: Formal Analyses, Visualisation, Writing - Original Draft; Tina B. Lonsdorf: Project administration, Conceptualization, Methodology, Writing - review \& editing, Funding acquisition, Supervision 


\section{Data Availability Statement}

The data that support the findings of this study are openly available in Zenodo at http://doi.org/10.5281/zenodo.5648055. 


\section{References}

Barlow, D. H., Sauer-Zavala, S., Carl, J. R., Bullis, J. R., \& Ellard, K. K. (2014). The nature, diagnosis, and treatment of neuroticism: Back to the future. Clin Psychol Sci, 2(3), 344365.

Bauer, E. A., MacNamara, A., Sandre, A., Lonsdorf, T. B., Weinberg, A., Morriss, J., \& Van Reekum, C. M. (2020). Intolerance of uncertainty and threat generalization: A replication and extension. Psychophysiology, 57(5), e13546.

Ben- Shakhar, G. (1985). Standardization within individuals: A simple method to neutralize individual differences in skin conductance. Psychophysiology, 22(3), 292-299.

Blumenthal, T. D., Cuthbert, B. N., Filion, D. L., Hackley, S., Lipp, O. V., \& van Boxtel, A. (2005). Committee report: Guidelines for human startle eyeblink electromyographic studies. Psychophysiology, 42(1), 1-15.

Bottesi, G., Noventa, S., Freeston, M. H., \& Ghisi, M. (2019). Seeking certainty about Intolerance of Uncertainty: Addressing old and new issues through the Intolerance of Uncertainty Scale-Revised. PloS One, 14(2), e0211929.

Boucsein, W., Fowles, D. C., Grings, W. W., Ben-Shakhar, G., Roth, W. T., \& Dawson, M. E. (2012). Publication recommendations for electrodermal measurements. Psychophysiology, 49(8), 1017-1034.

Briggs, J. F., \& Fava, D. A. (2016). Immediate extinction attenuates spontaneous recovery and reinstatement in a passive avoidance paradigm. Percept Mot Ski, 123(1), 5-16.

Carleton, R. N. (2016a). Fear of the unknown: One fear to rule them all? J Anxiety Disord, 41, 521.

Carleton, R. N. (2016b). Into the unknown: A review and synthesis of contemporary models involving uncertainty. J Anxiety Disord, 39, 30-43.

Carleton, R. N., Mulvogue, M. K., Thibodeau, M. A., McCabe, R. E., Antony, M. M., \& Asmundson, G. J. (2012). Increasingly certain about uncertainty: Intolerance of uncertainty across anxiety and depression. J Anxiety Disord, 26(3), 468-479.

Carleton, R. N., Norton, M. P. J., \& Asmundson, G. J. (2007). Fearing the unknown: A short version of the Intolerance of Uncertainty Scale. J Anxiety Disord, 21(1), 105-117.

Chin, B., Nelson, B. D., Jackson, F., \& Hajcak, G. (2016). Intolerance of uncertainty and startle potentiation in relation to different threat reinforcement rates. Int J Psychophysiol, 99, 7984.

Clark, D. A., \& Beck, A. T. (2011). Cognitive therapy of anxiety disorders: Science and practice: Guilford Press. 
Constantinou, E., Purves, K. L., McGregor, T., Lester, K. J., Barry, T. J., Treanor, M., ... \& Eley, T. C. (2021). Measuring fear: Association among different measures of fear learning. $J$ Behav Ther Exp Psychiatry, 70, 101618.

Craske, M. G., Treanor, M., Conway, C. C., Zbozinek, T., \& Vervliet, B. (2014). Maximizing exposure therapy: An inhibitory learning approach. Behav Res Ther, 58, 10-23.

Dunsmoor, J. E., Campese, V. D., Ceceli, A. O., LeDoux, J. E., \& Phelps, E. A. (2015). Noveltyfacilitated extinction: providing a novel outcome in place of an expected threat diminishes recovery of defensive responses. Biol psychiatry, 78(3), 203-209.

Freeston, M. H., Rhéaume, J., Letarte, H., Dugas, M. J., \& Ladouceur, R. (1994). Why do people worry? Pers Individ Differ, 17(6), 791-802.

Green, S. R., Kragel, P. A., Fecteau, M. E., \& LaBar, K. S. (2014). Development and validation of an unsupervised scoring system (Autonomate) for skin conductance response analysis. Int J Psychophysiol, 91(3), 186-193.

Grings, W. W., Lockhart, R. A., \& Dameron, L. E. (1962). Conditioning autonomic responses of mentally subnormal individuals. Psychol Monogr: Gen Appl, 76(39), 1.

Haaker, J., Golkar, A., Hermans, D., \& Lonsdorf, T. B. (2014). A review on human reinstatement studies: an overview and methodological challenges. Learn Mem, 21(9), 424-440.

Huff, N. C., Hernandez, J. A., Blanding, N. Q., \& LaBar, K. S. (2009). Delayed extinction attenuates conditioned fear renewal and spontaneous recovery in humans. Behav Neurosci, 123(4), 834.

Jacoby, R. J., \& Abramowitz, J. S. (2016). Inhibitory learning approaches to exposure therapy: A critical review and translation to obsessive-compulsive disorder. Clin Psychol Rev, 49, 28-40.

Jensen, D., Cohen, J. N., Mennin, D. S., Fresco, D. M., \& Heimberg, R. G. (2016). Clarifying the unique associations among intolerance of uncertainty, anxiety, and depression. Cogn Behav Ther, 45(6), 431-444. doi: 10.1080/16506073.2016.1197308

Johnson, J. S., Escobar, M., \& Kimble, W. L. (2010). Long-term maintenance of immediate or delayed extinction is determined by the extinction-test interval. Learn Mem, 17(12), 639644.

Kanen, J. W., Arntz, F. E., Yellowlees, R., Christmas, D. M., Price, A., Apergis-Schoute, A. M., . . . Robbins, T. W. (2020). Effect of tryptophan depletion on conditioned threat memory expression: role of intolerance of uncertainty. Biol psychiatry: Cognitive Neuroscience and Neuroimaging. 
Lipp, O. V. (2006). Human Fear Learning: Contemporary Procedures and Measurement. In M. G. Craske, D. Hermans, \& D. Vansteenwegen (Eds.), Fear and learning: From basic processes to clinical implications (pp. 37-51). American Psychological Association.

Lissek, S., Pine, D. S., \& Grillon, C. (2006). The strong situation: A potential impediment to studying the psychobiology and pharmacology of anxiety disorders. Biol Psychol, 72(3), 265-270. doi: 10.1016/j.biopsycho.2005.11.004

Lonsdorf, T. B., Klingelhöfer-Jens, M., Andreatta, M., Beckers, T., Chalkia, A., Gerlicher, A., . . Richter, J. (2019). Navigating the garden of forking paths for data exclusions in fear conditioning research. Elife, 8, e52465.

Lonsdorf, T. B., Menz, M. M., Andreatta, M., Fullana, M. A., Golkar, A., Haaker, J., . . Kruse, O. (2017). Don't fear 'fear conditioning': Methodological considerations for the design and analysis of studies on human fear acquisition, extinction, and return of fear. Neurosci Biobehav Rev, 77, 247-285.

Lonsdorf, T. B., \& Merz, C. J. (2017). More than just noise: Inter-individual differences in fear acquisition, extinction and return of fear in humans-Biological, experiential, temperamental factors, and methodological pitfalls. Neurosci Biobehav Rev, 80, 703728.

Lucas, K., Luck, C. C., \& Lipp, O. V. (2018). Novelty-facilitated extinction and the reinstatement of conditional human fear. Behav Res Ther, 109, 68-74.

Maren, S. (2014). Nature and causes of the immediate extinction deficit: a brief review. Neurobiology of Learning and Memory, 113, 19-24.

Merz, C. J., Hamacher-Dang, T. C., \& Wolf, O. T. (2016). Immediate extinction promotes the return of fear. Neurobiol learn mem, 131, 109-116.

McEvoy, P. M., \& Erceg-Hurn, D. M. (2016). The search for universal transdiagnostic and transtherapy change processes: Evidence for intolerance of uncertainty. $J$ Anxiety Disord, 41, 96-107.

McEvoy, P. M., Hyett, M. P., Shihata, S., Price, J. E., \& Strachan, L. (2019). The impact of methodological and measurement factors on transdiagnostic associations with intolerance of uncertainty: A meta-analysis. Clin Psychol Rev, 73, 101778. doi:10.1016/j.cpr.2019.101778

McNally, R. J. (2007). Mechanisms of exposure therapy: how neuroscience can improve psychological treatments for anxiety disorders. Clin Psychol Rev, 27(6), 750-759.

Mertens, G., \& Morriss, J. (2021). Intolerance of uncertainty and threat reversal: A conceptual replication of. Behav Res Ther, 103799. 
Morriss, J. (2019). What do I do now? Intolerance of uncertainty is associated with discrete patterns of anticipatory physiological responding to different contexts. Psychophysiology, 56(9), e13396.

Morriss, J., Bell, T., Biagi, N., Johnstone, T., \& Van Reekum, C. M. (2021). Intolerance of uncertainty is associated with heightened responding in the prefrontal cortex during cuesignalled uncertainty of threat. Cogn, Affect Behav Neurosci, 1-11.

Morriss, J., Christakou, A., \& Van Reekum, C. M. (2015). Intolerance of uncertainty predicts fear extinction in amygdala-ventromedial prefrontal cortical circuitry. Biol Mood Anx Disord, $5(1), 1$.

Morriss, J., Christakou, A., \& Van Reekum, C. M. (2016). Nothing is safe: Intolerance of uncertainty is associated with compromised fear extinction learning. Biol Psychol, 121, 187-193.

Morriss, J., Macdonald, B., \& Van Reekum, C. M. (2016). What is going on around here? Intolerance of uncertainty predicts threat generalization. PloS One, 11(5), e0154494.

Morriss, J., \& van Reekum, C. M. (2019). I feel safe when I know: Contingency instruction promotes threat extinction in high intolerance of uncertainty individuals. Behav Res Ther, $116,111-118$.

Morriss, J., Bradford, D., Wake, S., Biagi, N., Tanovic, E., Kaye, J., \& Joormann, J. (In Press). Intolerance of uncertainty and physiological responses during instructed uncertain threat: a multi-lab investigation. Biol Psychol.

Morriss, J., Wake, S., Elizabeth, C., \& van Reekum, C. M. (2021). I doubt it is safe: A metaanalysis of self-reported intolerance of uncertainty and threat extinction training. Biol psychiatry: Global Open Science.

Morriss, J., Wake, S., Lindner, M., McSorley, E., \& Dodd, H. (2020). How many times do I need to see to believe? The impact of intolerance of uncertainty and exposure experience on safety-learning and retention in young adults. Int J Psychophysiol, 153, 8-17.

Morriss, J., Zuj, D. V., \& Mertens, G. (2021). The role of intolerance of uncertainty in classical threat conditioning: Recent developments and directions for future research. Int $J$ Psychophysiol, 166, 116-126.

Norr, A. M., Oglesby, M. E., Capron, D. W., Raines, A. M., Korte, K. J., \& Schmidt, N. B. (2013). Evaluating the unique contribution of intolerance of uncertainty relative to other cognitive vulnerability factors in anxiety psychopathology. J Affect Disord, 151(1), 136-142. 
Oglesby, M. E., Allan, N. P., \& Schmidt, N. B. (2017). Randomized control trial investigating the efficacy of a computer-based intolerance of uncertainty intervention. Behav Res Ther, 95, 50-57.

Pittig, A., Treanor, M., LeBeau, R. T., \& Craske, M. G. (2018). The role of associative fear and avoidance learning in anxiety disorders: Gaps and directions for future research. Neurosci Biobehav Rev, 88, 117-140.

Scharfenort, R., Menz, M., \& Lonsdorf, T. B. (2016). Adversity-induced relapse of fear: Neural mechanisms and implications for relapse prevention from a study on experimentally induced return-of-fear following fear conditioning and extinction. Transl Psychiatry, 6(7), e858.

Scharfenort, R., \& Lonsdorf, T. B. (2016). Neural correlates of and processes underlying generalized and differential return of fear. Soc Cogn Affect Neurosci, 11(4), 612-620.

Schimmack, U. (2012). The ironic effect of significant results on the credibility of multiple-study articles. Psychol Methods, 17, 551.

Shihata, S., McEvoy, P. M., Mullan, B. A., \& Carleton, R. N. (2016). Intolerance of uncertainty in emotional disorders: What uncertainties remain? J Anxiety Disord, 41, 115-124.

Sjouwerman, R., Niehaus, J., Kuhn, M., \& Lonsdorf, T. B. (2016). Don't startle me-Interference of startle probe presentations and intermittent ratings with fear acquisition. Psychophysiology, 53(12), 1889-1899.

Sjouwerman, R., Scharfenort, R., \& Lonsdorf, T. B. (2020). Individual differences in fear acquisition: multivariate analyses of different emotional negativity scales, physiological responding, subjective measures, and neural activation. Sci Rep, 10, 15283.

Spielberger, C. D., Gorsuch, R. L., Lushene, R., Vagg, P. R., \& Jacobs, G. A. (1983). Manual for the State-Trait Anxiety Inventory. Palo Alto, CA: Consulting Psychologists Press.

Tanovic, E., Gee, D. G., \& Joormann, J. (2018). Intolerance of uncertainty: Neural and psychophysiological correlates of the perception of uncertainty as threatening. Clin Psychol Rev, 60, 87-99.

van der Heiden, C., Muris, P., \& van der Molen, H. T. (2012). Randomized controlled trial on the effectiveness of metacognitive therapy and intolerance-of-uncertainty therapy for generalized anxiety disorder. Behav Res Ther, 50(2), 100-109.

Wake, S., van Reekum, C. M., Dodd, H., \& Morriss, J. (2020). The impact of intolerance of uncertainty and cognitive behavioural instructions on safety learning. Cognit Ther Res, 44, 931-942. 
Wake, S., Morriss, J., Johnstone, T., Van Reekum, C. M., \& Dodd, H. (2021). Intolerance of uncertainty, and not social anxiety, is associated with compromised extinction of social threat. Behav Res Ther, 139, 103818.

Woods, A. M., \& Bouton, M. E. (2008). Immediate extinction causes a less durable loss of performance than delayed extinction following either fear or appetitive conditioning. Learn Mem, 15(12), 909-920. 


\section{Appendix}

\section{Methods}

\section{Participants}

Nine participants reported exclusion criteria in questionnaires completed subsequently to the experiment even though these were not reported at inclusion in the study. More precisely, three participants reported intake of medication (L-thyroxine: $n=2$; antihistamines: $n=1$ ). Two participants described suffering from migraines, but had no current migraine attack throughout the study. Four participants reported chronic diseases (bronchial asthma: $n=2$; duodenal ulcer: $n=1$; thyroid hypofunction: $n=1$ ). The decision to keep these participants in the sample was based on the assumption of no impact on results in those cases.

\section{Stimuli}

\section{Affect induction material}

To induce the affect (affect induction phase, see section Procedure), 16 neutral or 16 emotionally negative slides were presented for $6 \mathrm{~s}$ without ISIs. Each slide contained a picture $(270 \times 215 \mathrm{~mm})$ with a sentence above it (font: Calibri; font color: white; height of the sentences: $45 \mathrm{~mm}$ ). The added sentences on the emotionally negative slides emphasized the uncontrollability of the shown events (Pacheco-Unguetti, Acosta, Callejas, \& Lupianez, 2010), for instance, "Horrible accidents can happen to you everywhere". They were aimed at eliciting a fearful interpretation of the pictures and therefore intensifying their anxiety inducing effect. On the neutral slides, the sentences, which were added to align the conditions, consisted of boring facts such as "The eye color blue occurs particularly often in people with blond hair".

The anxiety inducing pictures had been chosen first and stemmed from the International affective picture system IAPS (Lang, Bradley, \& Cuthbert, 2008), the Nencki Affective Picture System NAPS (Marchewka, Żurawski, Jednoróg, \& Grabowska, 2014), and the EmoPicS database (Wessa et al., 2010). Selection criteria for the anxiety inducing pictures were a negative valence $(M=2.24, S D=1.31)$ and a high arousal $(M=7.10, S D=1.75)$. Next, the neutral pictures were matched on the basis of different criteria depending on the characteristics of each anxiety inducing picture. For example, one of the anxiety-inducing pictures showed a 
plane crash, whereas in the matched neutral picture people are boarding an airplane. The neutral pictures were characterized by a neutral valence $(M=5.29, S D=1.14)$ and a low arousal $(M=3.58, S D=1.67)$. A short validation study in which the material was tested beforehand confirmed the intended effects of the slides (data not shown).

\section{Procedure}

Immediately after extinction training, two startle probes were administered and participants were instructed shortly about the following affect induction phase on the computer screen (see Supplementary Figure 1). They were told that they would see some pictures with short texts, which might have emotional content. They were explicitly informed that no US will be presented. They were instructed to view the pictures and read the texts but no explicit information about the aim was provided to avoid demand effects (Lench et al., 2011). Until the twelfth participant, participants were randomly assigned to either the negative or neutral affect condition. From the thirteenth participant on, the two conditions were matched with respect to age, gender and State-Trait Anxiety Inventory State scores (STAI-S, see section Questionnaires on Day 1; Spielberger et al. 1983). After the affect induction, two startle probes were presented. 


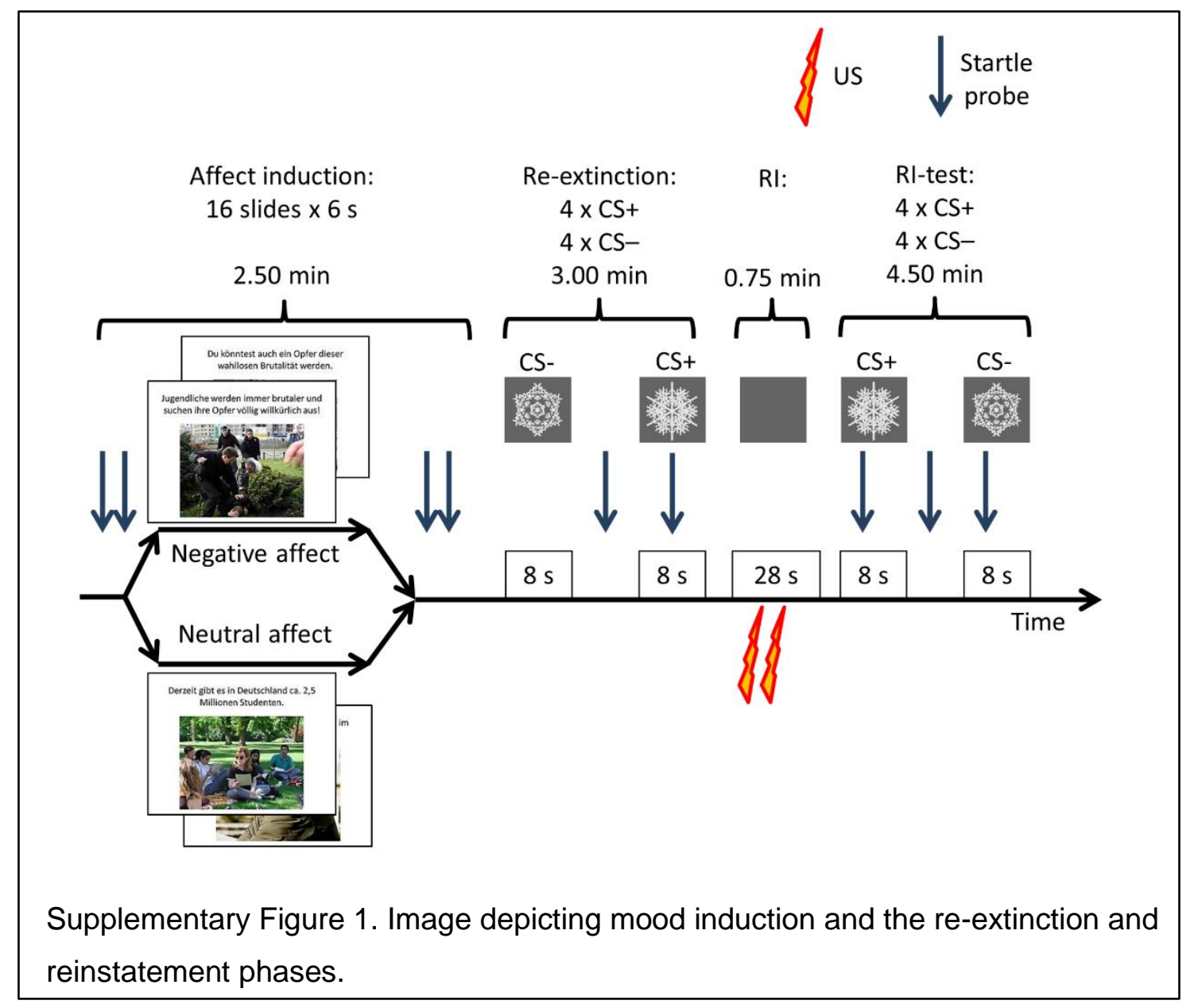

During the re-extinction phase, which immediately followed upon mood induction, none of the CSs was paired with the US during re-extinction. Three-quarters of the CS presentations were startled and participants had to complete one subjective fear rating of each CS-type. During the subsequent reinstatement, the gray background was shown. After $20 \mathrm{~s}$, two unannounced USs interleaved by $8 \mathrm{~s}$ were delivered.

To capture the transient reinstatement effect (Haaker et al., 2014; Scharfenort \& Lonsdorf, 2016), all CS presentations in the following reinstatement-test were startled. Two subjective fear ratings were presented (i.e., referring to i) the first presentation and ii) the last presentation in the test phase). Finally, fear ratings to the ITI and the gray background as well as ratings of the unpleasantness of the startle probes and the electrotactile stimulus were acquired by using the fear rating procedure (see main manuscript). Before leaving the 
laboratory, the experimenter ensured that participants who watched the emotionally negative slides felt comfortable.

\section{Measures}

Additional questionnaires of no interest to the present work

To check if negative emotions were successfully induced, the self-constructed Fundamental Emotions Questionnaire was applied. Participants were asked to rate to which extent they feel ten different emotions on a 9-point Likert scale anchored with not at all and very strong. To confirm the intended valence and arousal of the slides, the Self-Assessment Manikin (SAM; Lang, 1980) was used. Additional questionnaires of secondary interest were the state scale of the State-Trait Anxiety Inventory (Spielberger et al., 1983), Social Desirability Scale (SDS-CM; Crowne \& Marlowe, 1960), List of Threatening Experiences (LTE; Brugha et al., 1985), Childhood Trauma Questionnaire (CTQ; Bernstein \& Fink, 1998), Penn State Worry Questionnaire (PSWQ; Meyer et al., 1990) and self-constructed questions about parental anxiety and violent media use.

\section{Supplementary Analyses: the impact of IU and STAI-T on re-extinction and reinstatement-test}

Identical analyses to that presented in the main text were applied to the fear ratings, SCR, and auditory startle blink during i) re-extinction and ii) reinstatement. An additional factor of no interest was entered at level 1 in the MLMs (Group: negative mood induction, neutral mood induction).

\section{Results}

MLM statistics for Stimulus, Trial and interactions between Stimulus $x$ Trial are presented in the text. Interactions between Stimulus $x$ Trial will not be followed up, as they are beyond the scope of the manuscript.

Furthermore, MLM statistics for Stimulus x IUS/STAI-T interactions are also presented in the text and in Supplementary table 1. MLM statistics for main effects of STAI-T and IUS, as 
well as interactions between Trial $x$ IUS/STAI-T and Stimulus $x$ Trial $x$ IUS/STAI-T are

presented in Supplementary table 1 for transparency but are not presented in the text. Follow up tests such as MLMs with both IUS/STAI-T included and correlations between conditions and IUS/STAI-T are presented in the text only. 
Supplementary Table 1. IUS and STAI-T interactions from MLMs per phase and measure

\begin{tabular}{|c|c|c|c|c|c|c|}
\hline & \multicolumn{3}{|c|}{ Re-extinction } & \multicolumn{3}{|c|}{ Reinstatement } \\
\hline & Fear ratings & SCR magnitude & Auditory startle blink & Fear ratings & SCR magnitude & Auditory startle blink \\
\hline IUS & $\begin{array}{l}F(1,64.256)=.069 \\
p=.793\end{array}$ & $\begin{array}{l}F(1,71.232)=.512 \\
p=.477\end{array}$ & $\begin{array}{l}F(1,62.958)=.269 \\
p=.606\end{array}$ & $\begin{array}{l}F(1,63.454)=.944 \\
p=.335\end{array}$ & $\begin{array}{l}F(1,70.814)=1.530 \\
p=.220\end{array}$ & $\begin{array}{l}F(1,63.772)=.709 \\
p=.403\end{array}$ \\
\hline STAI-T & $\begin{array}{l}F(1,64.155)=.114 \\
p=.736\end{array}$ & $\begin{array}{l}F(1,70.388)=.048 \\
p=.827\end{array}$ & $\begin{array}{l}F(1,81.562)=2.037 \\
p=.157\end{array}$ & $\begin{array}{l}F(1,63.793)=.376 \\
p=.542\end{array}$ & $\begin{array}{l}F(1,71.164)=.027 \\
p=.869\end{array}$ & $\begin{array}{l}F(1,60.287)=.001 \\
p=.977\end{array}$ \\
\hline $\begin{array}{l}\text { Stimulus } x \\
\text { IUS }\end{array}$ & $\begin{array}{l}F(1,61.676)=2.106 \\
p=.152\end{array}$ & $\begin{array}{l}F(1,361.849)=2.104 \\
p=.148\end{array}$ & $\begin{array}{l}F(1,296.732)=.460 \\
p=.498\end{array}$ & $\begin{array}{l}F(1,122.430)=10.783 \\
p=.001\end{array}$ & $\begin{array}{l}F(1,392.243)=.014 \\
p=.906\end{array}$ & $\begin{array}{l}\mathrm{F}(1,389.750)=.479 \\
\mathrm{p}=.489\end{array}$ \\
\hline $\begin{array}{l}\text { Stimulus } x \\
\text { STAI-T }\end{array}$ & $\begin{array}{l}F(1,64.698)=.379 \\
p=.540\end{array}$ & $\begin{array}{l}F(1,362.142)=.196 \\
p=.658\end{array}$ & $\begin{array}{l}F(1,293.815)=.427 \\
p=.514\end{array}$ & $\begin{array}{l}F(1,122.913)=1.634 \\
p=.204\end{array}$ & $\begin{array}{l}F(1,391.130)=.699 \\
p=.404\end{array}$ & $\begin{array}{l}\mathrm{F}(1,391.812)=.512 \\
\mathrm{p}=.475\end{array}$ \\
\hline Trial x IUS & - & $\begin{array}{l}F(3,186.129)=1.416 \\
p=.240\end{array}$ & $\begin{array}{l}F(2,202.156)=1.823 \\
p=.164\end{array}$ & $\begin{array}{l}F(1,122.435)=.151 \\
p=.698\end{array}$ & $\begin{array}{l}\mathrm{F}(3,239.963)=.844 \\
\mathrm{p}=.471\end{array}$ & $\begin{array}{l}\mathrm{F}(3,205.668)=.744 \\
\mathrm{p}=.510\end{array}$ \\
\hline $\begin{array}{l}\text { Trial } x \\
\text { STAI-T }\end{array}$ & - & $\begin{array}{l}F(3,185.190)=.808 \\
p=.491\end{array}$ & $\begin{array}{l}F(2,207.487)=1.256 \\
p=.287\end{array}$ & $\begin{array}{l}F(1,123.216)=.761 \\
p=.385\end{array}$ & $\begin{array}{l}F(3,240.918)=.844 \\
p=.471\end{array}$ & $\begin{array}{l}F(3,193.952)=1.650 \\
p=.179\end{array}$ \\
\hline $\begin{array}{l}\text { Stimulus } x \\
\text { Trial } x \text { IUS }\end{array}$ & - & $\begin{array}{l}F(3,186.129)=1.323 \\
p=.268\end{array}$ & $\begin{array}{l}F(2,202.806)=3.050 \\
p=.050\end{array}$ & $\begin{array}{l}F(1,123.338)=1.904 \\
p=.170\end{array}$ & $\begin{array}{l}F(3,239.924)=.125 \\
p=.945\end{array}$ & $\begin{array}{l}F(3,206.786)=5.129 \\
p=.002\end{array}$ \\
\hline $\begin{array}{l}\text { Stimulus } x \\
\text { Trial } x \\
\text { STAI-T }\end{array}$ & - & $\begin{array}{l}F(3,185.190)=1.184 \\
p=.317\end{array}$ & $\begin{array}{l}F(2,207.791)=2.652 \\
p=.073\end{array}$ & $\begin{array}{l}F(1,123.175)=1.035 \\
p=.311\end{array}$ & $\begin{array}{l}F(3,240.808)=.611 \\
p=.609\end{array}$ & $\begin{array}{l}F(3,194.535)=1.784 \\
p=.152\end{array}$ \\
\hline
\end{tabular}

Note. MLM statistics for Stimulus $x$ IUS/STAI-T interactions are also presented in the text. MLM statistics for main effects of STAI-T and IUS, as well as interactions between Trial $x$ IUS/STAI-T and Stimulus $x$ Trial $x$ IUS/STAI-T are presented in this table for transparency but are not presented in the text. Entries in the table that are formatted in bold indicate significance. All effects remained significant when controlling for IUS or STAI-T. 


\section{Questionnaires}

The negative and neutral mood induction groups did not significantly differ in IUS $[t(62)=.345, p$ $=.731]$ or STAI-T $[t(62)=1.172, p=.246]$ scores.

\section{Re-extinction}

Fear ratings: No effect of stimulus type was found during re-extinction [Stimulus, $F(1,61.926)=$ $1.337, p=.252$; see Supplementary Figure 2]. For the fear ratings, no significant interactions between Stimulus x IUS or Stimulus x STAI-T were found (see Supplementary table 1).

SCR: No effect of Stimulus or interaction between Stimulus $x$ Trial emerged during re-extinction [Stimulus, $F(1,348.092)=.197, p=.658$; Stimulus $\times$ Trial, $F(3,180.865)=.928, p=.428$; see Supplementary Figure 2]. SCR habituated across trials [Trial, $F(3,180.865)=2.965, p=.033$ ]. For SCR, no significant interactions between Stimulus x IUS or Stimulus x STAI-T were found (see Supplementary table 1).

Startle: No effect of Stimulus or interaction between Stimulus x Trial emerged during reextinction [Stimulus, $F(1,297.834)=.625, p=.430$; Stimulus $\times$ Trial, $F(2,205.515)=.352, p=$ .703; see Supplementary Figure 2]. Startle habituated across trials [Trial, $F(2,205.370)=9.931$, $p<.001]$. For startle, no significant interactions between Stimulus $\times$ IUS or Stimulus $\times$ STAI-T were found (see Supplementary table 1). 


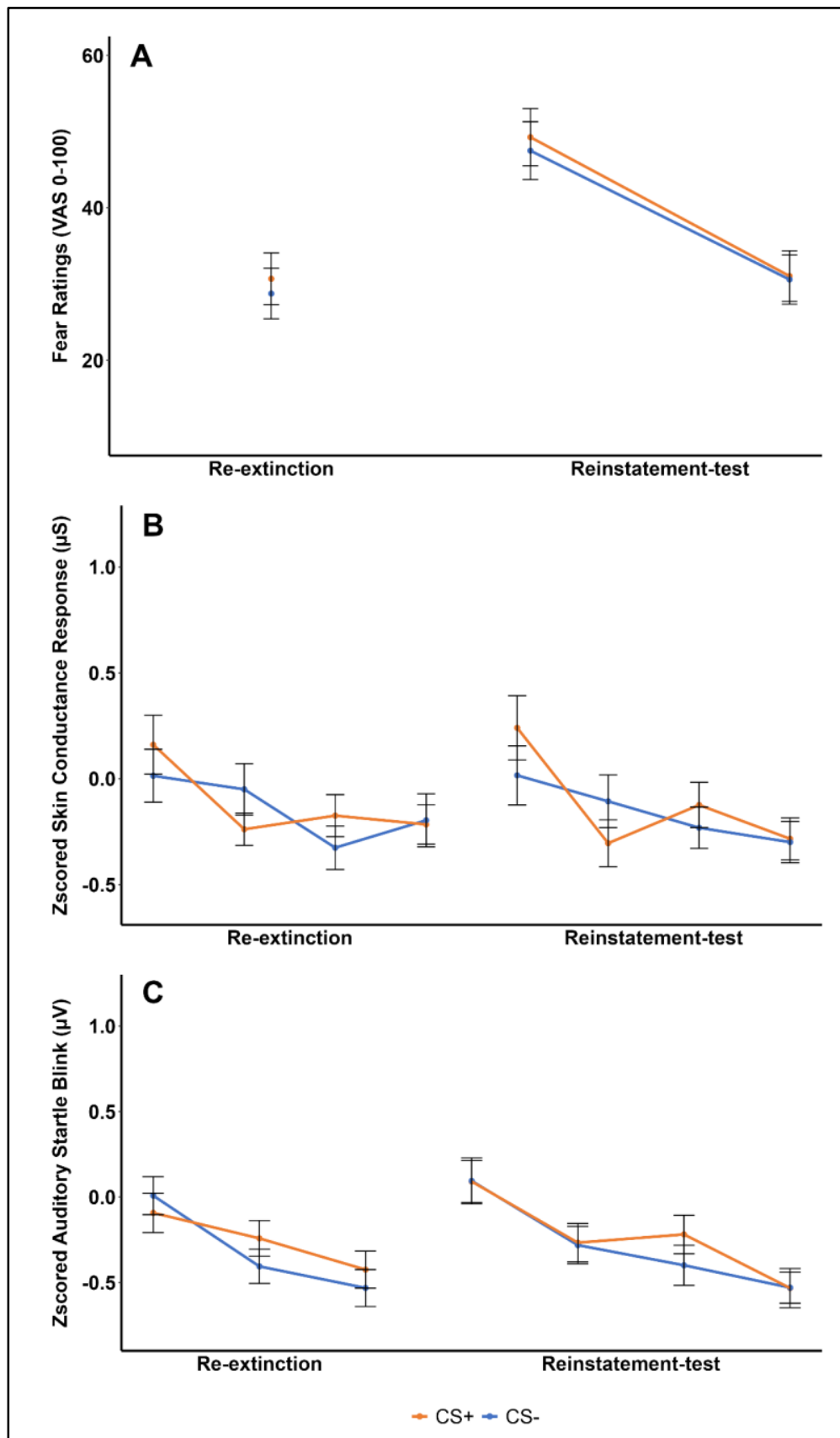

Supplementary Figure 2. Single-trial data during re-extinction and reinstatement-test for fear ratings (A), SCR (B), and auditory startle blink (C). SCR and auditory startle blink data were zscored. Data represent \pm standard error of the mean.

\section{Reinstatement-test}

Fear ratings: No effect of Stimulus or interaction between Stimulus $x$ Trial was found during reinstatement-test [Stimulus, $F(1,114.203)=.655, p=.420$; Stimulus $\times$ Trial, $F(1,115.366)=$ 
$.256, p=.614$; see Supplementary Figure 2]. Fear ratings habituated across trials [Trial, $F(1,114.309)=63.988, p<.001]$

A Stimulus $x$ IUS interaction emerged both when IUS was entered into the model alone $[F(1,122.430)=10.783, p=.001]$ or together with STAI-T $[F(1,113.796)=7.963, p=.006]$.

Follow up correlational tests demonstrated that higher IUS was significantly positively associated with greater differential fear ratings to the CS+ vs. CS- $[r(62)=.357, p=.004$; see Supplementary Figure 3]. IUS was not significantly associated with fear ratings to the CS+ $r(62)$ $=.218, p=.084]$ or CS- $[r(62)=.004, p=.976]$.

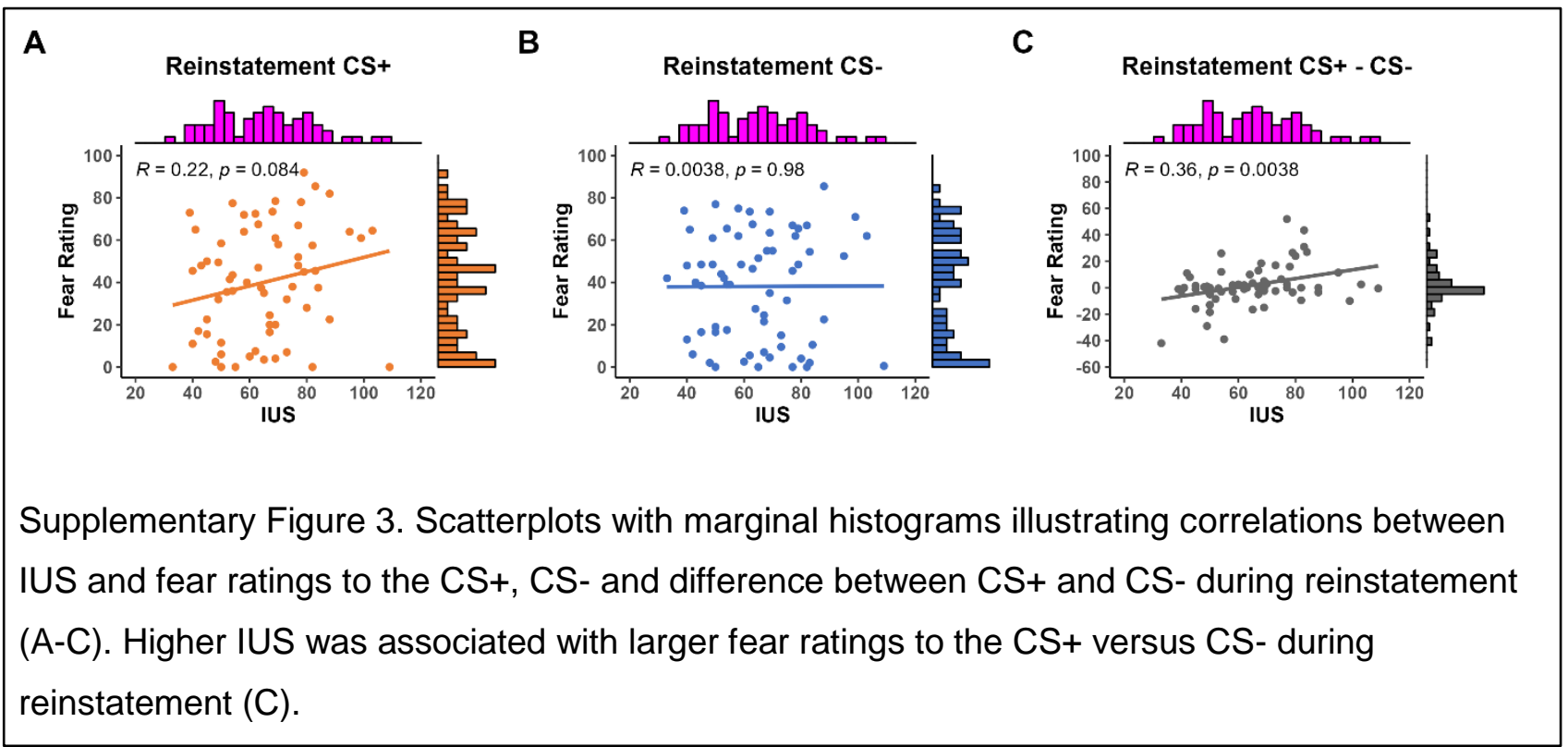

For the fear ratings, no significant interaction between Stimulus STAI-T was observed (see Supplementary table 1).

SCR: No effect of Stimulus or interaction between Stimulus $x$ Trial emerged during reinstatement [Stimulus, $F(1,393.467)=.233, p=.630$; Stimulus $x$ Trial, $F(3,237.837)=1.623$, $p=.185$; see Supplementary Figure 2]. As in other phases, SCR habituated across trials [Trial, $F(3,237.966)=4.462, p=.005]$. For SCR, no significant interactions between Stimulus x IUS or Stimulus $x$ STAI-T were found (see Supplementary table 1). 
Startle: No effect of Stimulus or interaction between Stimulus $x$ Trial was found during reinstatement [Stimulus, $F(1,388.850)=.066, p=.798$; Stimulus $\times$ Trial, $F(3,202.488)=.505, p$ $=.679$; see Supplementary Figure 2]. Auditory startle blink habituated across trials [Trial, $F(3$, $201.933)=11.132, p<.001]$. For startle, no significant interactions between Stimulus $x$ IUS or Stimulus $\times$ STAI-T were found (see Supplementary table 1).

\section{Robustness analyses}

To check for possible confounders, associations between IUS as well as STAI-T scores and CS-US contingency awareness, US intensity, US and startle probe aversiveness on both experimental days and mean SCRs to the US during acquisition training were investigated.

Seventeen participants were classified as unaware. According to the results of twosample t-tests, there was no difference in IUS or STAI-T scores between aware (IUS: $M=$ 65.66, $S D=16.38$; STAI-T: $M=38.26, S D=9.22$ ) and non-aware (IUS: $M=63.44, S D=19.12$; STAI-T: $M=41.72, S D=10.80$ ) participants [IUS: $t(63)=0.466, p=.643$; STAI-T: $t(63)=$ 1.293, $p=.201]$. Moreover, there were no significant correlations (Pearson correlation coefficients) between IUS or STAI-T scores and US intensity on day 1 [IUS: $r(63)=-.060, p=$ .634; STAI-T: $r(63)=-.061, p=.627$ ] as well as on day 2 [IUS: $r(63)=.086, p=.494$; STAI-T: $r(63)=.155, p=.216$ ], aversiveness of US [IUS: $r(63)=.120, p=.342$; STAI-T: $r(63)=.117, p=$ .354], aversiveness of the startle probes on day 1 [IUS: $r(63)=.100, p=.426$; STAI-T: $r(63)=$ $.168, p=.181$ ] as well as on day 2 [IUS: $r(63)=.102, p=.420$; STAI-T: $r(63)=.088, p=.484$ ] and mean SCR to the US [IUS: $r(61)=.076, p=.552$; STAI-T: $r(61)=-.048, p=.710$ ]. Accordingly, results of these robustness analyses did not indicate confounding effects of these variables. 


\section{References}

Bernstein, D. P., \& Fink, L. A. (1998). CTQ: Childhood Trauma Questionnaire: A retrospective self-report. Manual. San Antonio, TX: Psychological Cooperation.

Brugha, T., Bebbington, P., Tennant, C., \& Hurry, J. (1985). The List of Threatening Experiences: A subset of 12 life event categories with considerable long-term contextual threat. Psychol Med, 15(01), 189-194. https://doi.org/10.1017/S003329170002105X

Crowne, D. P., \& Marlowe, D. (1960). A new scale of social desirability independent of psychopathology. J Consult Psychol, 24(4), 349-354. https://doi.org/10.1037/h0047358

Haaker, J., Golkar, A., Hermans, D., \& Lonsdorf, T. B. (2014). A review on human reinstatement studies: An overview and methodological challenges. Learn Mem, 21(9), 424-440. https://doi.org/10.1101//m.036053.114

Lang, P. J. (1980). Behavioral treatment and bio-behavioral assessment: Computer applications. In J. B. Sidowski, J. H. Johnson, \& E. A. Williams (Eds.), Technology in mental health care delivery systems (pp. 119-137). Norwood, NJ: Ablex. Retrieved from https://www.scienceopen.com/document?vid=50ea4270-06a8-432a-973c6de76e9e7e34

Lang, P. J., Bradley, M. M., \& Cuthbert, B. N. (2008). International affective picture system (IAPS): Affective ratings of pictures and instruction manual. Technical Report A-8. University of Florida, Gainsville, FL.

Lench, H. C., Flores, S. A., \& Bench, S. W. (2011). Discrete emotions predict changes in cognition, judgment, experience, behavior, and physiology: A meta-analysis of experimental emotion elicitations. Psychol Bull, 137(5), 834-855.

https://doi.org/10.1037/a0024244

Marchewka, A., Żurawski, Ł., Jednoróg, K., \& Grabowska, A. (2014). The Nencki Affective Picture System (NAPS): Introduction to a novel, standardized, wide-range, high-quality, realistic picture database. Behav Res Methods, 46(2), 596-610.

https://doi.org/10.3758/s13428-013-0379-1 
Meyer, T. J., Miller, M. L., Metzger, R. L., \& Borkovec, T. D. (1990). Development and validation of the penn state worry questionnaire. Behav Res Ther, 28(6), 487-495. https://doi.org/10.1016/0005-7967(90)90135-6

Pacheco-Unguetti, A. P., Acosta, A., Callejas, A., \& Lupianez, J. (2010). Attention and anxiety: Different attentional functioning under state and trait anxiety. Psychol Sci, 21(2), 298304. https://doi.org/10.1177/0956797609359624

Scharfenort, R., \& Lonsdorf, T. B. (2016). Neural correlates of and processes underlying generalized and differential return of fear. Soc Cogn Affect Neurosci, 11(4), 612-620. https://doi.org/10.1093/scan/nsv142

Spielberger, C. D., Gorsuch, R. L., Lushene, R., Vagg, P. R., \& Jacobs, G. A. (1983). Manual for the State-Trait Anxiety Inventory (From Y). Palo Alto, CA: Consulting Psychologists Press.

Wessa, M., Kanske, P., Neumeister, P., Bode, K., Heissler, J., \& Schönfelder, S. (2010). EmoPics: Subjektive und psychophysiologische Evaluation neuen Bildmaterials für die klinisch-biopsychologische Forschung. Zeitschrift für Klinische Psychologie und Psychotherapie, Supplementum, 1(11), 77. 